\title{
OPEN Variations in morphology, physiology, and multiple bioactive constituents of Lonicerae Japonicae Flos under salt stress
}

\author{
Zhichen Cai ${ }^{1}$, Xunhong Liu ${ }^{1,2,3 凶}$, Huan Chen ${ }^{1}$, Rong Yang ${ }^{1}$, Jiajia Chen ${ }^{1}$, Lisi Zou ${ }^{1}$, \\ Chengcheng Wang ${ }^{1}$, Jiali Chen ${ }^{1}$, Mengxia Tan ${ }^{1}$, Yuqi Mei ${ }^{1}$ \& Lifang Wei ${ }^{1}$
}

Lonicerae Japonicae Flos (LJF) is an important traditional Chinese medicine for the treatment of various ailments and plays a vital role in improving global human health. However, as unable to escape from adversity, the quality of sessile organisms is dramatically affected by salt stress. To systematically explore the quality formation of LJF in morphology, physiology, and bioactive constituents' response to multiple levels of salt stress, UFLC-QTRAP-MS/MS and multivariate statistical analysis were performed. Lonicera japonica Thunb. was planted in pots and placed in the field, then harvested after 35 days under salt stress. Indexes of growth, photosynthetic pigments, osmolytes, lipid peroxidation, and antioxidant enzymes were identified to evaluate the salt tolerance in LJF under different salt stresses $(0,100,200$, and $300 \mathrm{mM} \mathrm{NaCl})$. Then, the total accumulation and dynamic variation of $\mathbf{4 7}$ bioactive constituents were quantitated. Finally, Partial least squares discrimination analysis and gray relational analysis were performed to systematically cluster, distinguish, and evaluate the samples, respectively. The results showed that $100 \mathrm{mM} \mathrm{NaCl}$ induced growth, photosynthetic, antioxidant activities, osmolytes, lipid peroxidation, and multiple bioactive constituents in LJF, which possessed the best quality. Additionally, a positive correlation was found between the accumulation of phenolic acids with antioxidant enzyme activity under salt stress, further confirming that phenolic acids could reduce oxidative damage. This study provides insight into the quality formation and valuable information to improve the LJF medicinal value under salt stress.

Agricultural production is seriously threatened by various environmental stresses, such as excessive salt ${ }^{1}$, pathogen infection ${ }^{2}$, drought ${ }^{3}$, and nutrient ${ }^{4}$, etc. It is predicted that crop productivity will decrease by $50 \%$ in many parts of the world to $2050^{5}$. Among them, excessive salt is becoming one of the most detrimental and diffuse environmental stress and retards seed germination, plant growth, and productivity ${ }^{6}$. Medicinal plants, which are important crops to resist and cure diseases, are also under the threat. Hence, the quality evaluation and quality formation mechanism of medicinal materials under salt stress should be paid attention.

Lonicera japonica Thunb., which is native to the countries of eastern Asia and widely distributed in most parts of China, is one of the most important vine species of the Caprifoliaceae family. Therein, the flower bud or initial flower is documented as traditional Chinese medicine (TCM) in the Chinese Pharmacopoeia (2015 edition), named Lonicerae Japonicae Flos (LJF), and it is known as 'jin-yin-hua' in Chinese. Recently, LJF has also been applied to suppress SARS coronavirus ${ }^{7,8}$ and influenza A viruses (H1N1, H5N1, and H7N9) ${ }^{9}$, which pose a substantial threat to public health worldwide. Besides, its traditional Chinese prescriptions, Lianhua qingwen capsule have been approved for the treatment of COVID-19. Meanwhile, it is also widely used as healthy food, cosmetics, and so on ${ }^{7}$. And the market demand is increasing day by day. Modern phytochemical and pharmacological studies show that more than 200 compounds including organic acids, flavonoids, iridoids, volatile oils have been identified in $\mathrm{LJF}^{7,10}$, and these compounds possess multiple biological activities. For example, phenolic compounds have been frequently reported to display a vital role in anti-aging, anti-inflammatory, anti-oxidation, anti-proliferative, etc. ${ }^{11}$. Products rich in flavonoids are also recommended to reduce the risk of chronic diseases,

\footnotetext{
${ }^{1}$ College of Pharmacy, Nanjing University of Chinese Medicine, Nanjing 210023, China. ${ }^{2}$ Collaborative Innovation Center of Chinese Medicinal Resources Industrialization, Nanjing 210023, China. ${ }^{3}$ National and Local Collaborative Engineering Center of Chinese Medicinal Resources Industrialization and Formulae Innovative Medicine, Nanjing 210023, China. ${ }^{\bowtie}$ email: liuxunh1959@163.com
} 
such as coronary heart disease, heart disease, cancer, and diabetes ${ }^{11}$. Moreover, iridoid glycosides are responsible for antibacterial ${ }^{12}$, anti-allergic ${ }^{13}$, hepatoprotective ${ }^{14}$, and other pharmacological properties. Iridoid possess neuroprotective ${ }^{15}$, anti-thrombotic, and anti-inflammatory effects ${ }^{16}$. The accumulation and synthesis of bioactive constituents mainly depend on satisfactory growing conditions. And salt stress can stimulate the synthesis of chlorogenic acid and phenolic constituents ${ }^{17,18}$, which are the main active compounds in LJF. Hence, it is supposed that moderate salinity might be able to improve the quality formation of LJF.

Although the quality evaluation of LJF has been reported previously ${ }^{19,20}$, studies on the quality formation of LJF under salt stress are still scanty. Multiple physiological and biochemical responses under salt stress have been monitored in a variety of crops and medicinal plants ${ }^{21,22}$; however, there is still limited information on the association of morphology, physiology, and bioactive constituents with salinity in LJF. To the best of our knowledge, the experiments of LJF under the salt stress are mostly executed with hydroponics or potted plants, focusing on the alterations of a single or one class of component concentration ${ }^{17,23}$, which lack ecological proof and practical value. Because the quality formation of TCM is affected by various factors in nature, while single or one class of constituents cannot completely represent the quality of complicated TCM. For these reasons, we aim to investigate the variations of morphology, physiology, and multiple bioactive constituents in LJF under different salt stresses; developing a simulation approach to predict the quality of LJF associated with salinity through field trials; and analyze the correlation between antioxidant enzyme activity and total phenolic content in anti-oxidative stress.

Up to now, there is no public report on the changes in morphology, physiology, and multiple bioactive constituents in LJF under different salt stresses $(0,100,200,300 \mathrm{mM} \mathrm{NaCl}$, respectively). Here, the morphological changes of LJF during the growth process under different salt stresses were recorded; Physiological indexes including photosynthetic pigments, osmolytes, lipid peroxidation, and antioxidant enzymes activity were evaluated. Next, the total accumulation and dynamic variation of 47 bioactive constituents including 13 amino acids, 4 nucleosides, 12 organic acids, 12 flavonoids, and 6 iridoids were quantitated by ultra-fast liquid chromatography coupled with triple quadrupole/linear ion trap tandem mass spectrometry (UFLC-QTRAP-MS/MS). Moreover, multivariate statistical analysis was used to evaluate the quality of LJF. Partial least squares discrimination analysis (PLS-DA) and gray relational analysis (GRA) was employed to systematically cluster, distinguish, and evaluate the samples, respectively. Simultaneously, the correlation between antioxidant enzyme activity and total phenolic content in anti-oxidative stress was also analyzed and discussed. This study can provide insights into the quality formation of LJF under salt stress and novel clues for improving the quality of LJF.

\section{Materials and methods}

Plant materials and salt treatments. The experimental site was located in Medicinal Botanical Garden of Nanjing University of Chinese Medicine (north latitude $118^{\circ} 57^{\prime} 1^{\prime \prime}$, east longitude $32^{\circ} 6^{\prime} 5^{\prime \prime}$ ), Nanjing, China. The two-year-old major roots of $L$. japonica were excavated from Henan province in December 2018. The botanical origins were identified by Professor Xunhong Liu (Department for Authentication of Chinese Medicines, Nanjing University of Chinese Medicine); these plants were planted in plastic plots $(50 \mathrm{~cm}$ height, $34 \mathrm{~cm}$ of top diameter, and $26 \mathrm{~cm}$ of bottom diameter) with approximately $25 \mathrm{~kg}$ soil (texture: loam; organic carbon: $36.6 \mathrm{~g} /$ $\mathrm{kg}$; cation exchange capacity: $17.0 \mathrm{cmol} / \mathrm{kg} ; \mathrm{pH}: 5.0$ ) and placed in the open air before salt stress treatment. A shed blocking off rainwater was installed when the salt treatment began, other conditions were almost the same as the opened-air environment.

L. japonica was allowed to grow naturally, until these plants were alive and germinated. Then four concentrations of saline solution $0 \mathrm{mM}$ (control, $0 \mathrm{~g} / \mathrm{L} \mathrm{NaCl}$ ), $100 \mathrm{mM}$ (low salt stress, $5.85 \mathrm{~g} / \mathrm{L} \mathrm{NaCl}$ ), $200 \mathrm{mM}$ (medium salt stress, $11.7 \mathrm{~g} / \mathrm{L} \mathrm{NaCl}$ ), and $300 \mathrm{mM}$ (high salt stress, $17.55 \mathrm{~g} / \mathrm{L} \mathrm{NaCl}$ ) were conducted from 24 April 2019 to 29 May 2019. The treatments were designed with 5 replicates at each concentration. To avoid the osmotic shock, the concentration was increased gradually until the set salt concentration was reached. The stress treatment was executed at a rate of $2 \mathrm{~L}$ per pot every three days. The flower buds and leaves were collected from 5 randomly selected plants in May 2019. And then cleaned with phosphate buffer saline (PBS), immediately frozen at $-80^{\circ} \mathrm{C}$ for the subsequent experiments. Some for physiological experiments, some for quantitative analysis, and the rest were used as voucher specimens.

Growth parameters. The growth process of L. japonica before salt stress was showed in Fig. S1. Leaf diameter and flower bud length were determined during the blooming stage. Plant height and fresh weight of shoots per plant were measured on the last day of harvest. The salt stress injury can be divided into five grades, as follows:

Grade 0: no symptoms of salt stress;

Grade 1: a few leaf tips, leaf margins, and veins turn yellow;

Grade 2: about half of the leaf tip, wizen leaf edge;

Grade 3: most of the leaves become yellow and fall;

Grade 4: the branches dry up and the leaves fall.

Extraction and assay of pigment. The contents of chlorophylls and carotenoids were evaluated according to the study of Lichtenthaler ${ }^{24}$. The fresh leaf of L. japonica $(0.5 \mathrm{~g})$ under four different salt concentrations was collected and homogenized with acetone $(80 \%, \mathrm{v} / \mathrm{v})$. The method was as follows: Firstly, mix leaves with $50 \mathrm{~mL} 80 \%$ acetone in the flasks and ultrasonic with $5 \mathrm{~min}$. Secondly, centrifuge at $8050 \mathrm{~g}$ for $10 \mathrm{~min}$. Then absorbance of samples was determined at 441, 646, 652, and $663 \mathrm{~nm}$ using UV-Vis spectrophotometer (DENO- 
VIX DS-11, USA). The contents of photosynthetic pigments (chlorophyll a, b, total chlorophyll, and carotenoids) were calculated according to the following formula:

$$
\begin{aligned}
\text { Chlorophyll a }(\mathrm{mg} / \mathrm{g} \mathrm{FW}) & =(12.21 \times \mathrm{E} 663-2.81 \times \mathrm{E} 649) \times(\mathrm{V} / 1000 \times \mathrm{M}) \\
\text { Chlorophyll b }(\mathrm{mg} / \mathrm{g} \mathrm{FW}) & =(20.13 \times \mathrm{E} 646-5.03 \times \mathrm{E} 663) \times(\mathrm{V} / 1000 \times \mathrm{M}) \\
\text { Total chlorophyll }(\mathrm{mg} / \mathrm{g} \mathrm{FW}) & =(27.8 \times \mathrm{E} 652) \times(\mathrm{V} / 1000 \times \mathrm{M}) \\
\text { Carotenoids }(\mathrm{mg} / \mathrm{g} \mathrm{FW}) & =[(1000 \times \mathrm{E} 441)-(3.27 \times \text { Chlorophyll a })-(104 \times \text { Chlorophyll b })] \times[(\mathrm{V} / 1000 \times(\mathrm{M} \times 229)]
\end{aligned}
$$

Proline, soluble proteins, total AA, and MDA assay. Fresh leaf samples $(0.1 \mathrm{~g})$ were powdered with a $1 \mathrm{~mL}$ sulfosalicylic acid dihydrate (SA) and transferred to a tube for $10 \mathrm{~min}$ heating in the boiling water bath. Afterward, centrifuged at $10,000 \mathrm{~g}$ for $10 \mathrm{~min}$, then the supernatant was collected to detect proline concentrations at $520 \mathrm{~nm}$ using UV-Vis spectrophotometer (DENOVIX DS-11, USA) ${ }^{25,26}$. Dilute $1 \mathrm{mg}$ standard substance to $15,10,8,6,4,2,1,0 \mu \mathrm{g} / \mathrm{ml}$, respectively. Then establishing a standard curve according to the absorption value and concentration of the standard substance.

Fresh leaf samples $(0.5 \mathrm{~g})$ were homogenized and extracted by $4.5 \mathrm{~mL}$ PBS (0.1 mol/L, PH: 7.4) in an ice-water bath. After centrifugation, the supernatant, $563 \mu \mathrm{g} / \mathrm{mL}$ protein standard solution, and blank solution (double distilled water) were detected using a UV-Vis spectrophotometer (DENOVIX DS-11, USA) at $562 \mathrm{~nm}$, which could display the concentration of protein ${ }^{27}$.

Fresh leaf tissues $(0.5 \mathrm{~g})$ were homogenized and $4.5 \mathrm{~mL}$ normal saline (NS) was added, then centrifuged at $685 \mathrm{~g}$ for $10 \mathrm{~min}$, and then took the supernatant to be measured. $1 \mathrm{~mL}$ supernatant mixed with $2 \mathrm{~mL}$ amino acid reaction solution and $1 \mathrm{~mL}$ amino acid chromogenic agent, and the mixture was centrifuged at $685 \mathrm{~g}$ for $10 \mathrm{~min}$, the supernatant was then taken to measure the absorption value at $650 \mathrm{~nm}$ using UV-Vis spectrophotometer (DENOVIX DS-11, USA) ${ }^{25}$.

The content of MDA was measured by Thibabituric Acid (TBA) method ${ }^{28}$, which represents lipid peroxidation. $0.5 \mathrm{~g}$ fresh leaf tissues were grounded with $4.5 \mathrm{~mL}$ TBA, and centrifuged at $685 \mathrm{~g}$ for $10 \mathrm{~min} ; 2 \mathrm{~mL}$ aliquot of the supernatant was mixed with $0.5 \% \mathrm{TBA}$, and then heated in boiling water for $40 \mathrm{~min}$, quickly cooled with ice-bath. After centrifugation at $685 \mathrm{~g}$ for $10 \mathrm{~min}$, the supernatant was prepared for the assay of MDA and the absorbance at $532 \mathrm{~nm}$ was recorded.

Enzyme extraction and activities assay. The fresh leaf of L. japonica under different salt stresses were collected for determining the antioxidant activity. The leaves $(0.5 \mathrm{~g})$ were homogenized with $4.5 \mathrm{~mL}$ PBS in an ice water bath and centrifuged at $350 \mathrm{~g}$ (catalase, CAT), $685 \mathrm{~g}$ (superoxide dismutase, SOD and peroxidase, POD), and $5595 \mathrm{~g}$ (ascorbate peroxidase, APX) for $10 \mathrm{~min}$, respectively. The supernatant was used to examine the activities of the enzyme.

The activity of SOD was assayed at $550 \mathrm{~nm}$ using the hydroxylamine method; the activity of POD was determined at $420 \mathrm{~nm}$ according to the colorimetric method ${ }^{25,26}$; the activity of CAT was measured at $405 \mathrm{~nm}$ based on the ammonium molybdate method, and the activity of APX was determined at $290 \mathrm{~nm}$. All of the experiments were carried out by assay kits. The amount of $200 \mu \mathrm{L}$ reaction solution was measured by multi-mode microplate reader using UV-Vis spectrophotometer (DENOVIX DS-11, USA).

Chemicals and reagents. The purity of 47 standard compounds was more than $98 \%$; the structures and source of 47 standard compounds were shown in Fig. S2 and Table S1; All of the chemicals and reagents were reported in our previous study ${ }^{29,30}$.

Preparation of sample solutions. Fresh flower buds were harvested on the 20th, 25th, and 35th day, respectively, and then placed under natural dry conditions. All dried flower buds were powdered and sieved through 50 mesh. After accurately weighed powder samples $(1.0 \mathrm{~g})$ were extracted using ultra-sonication with $40 \mathrm{~mL} \mathrm{70 \%} \mathrm{methanol} \mathrm{for} 45 \mathrm{~min}$, the loss of solvents was compensated with $70 \%$ methanol and mixed well. Then centrifuged at $8050 \mathrm{~g}$ for $10 \mathrm{~min}$ and filtered $0.22 \mathrm{~nm}$ membrane filters. The supernatants were stored in a sample bottle at $4{ }^{\circ} \mathrm{C}$ before UFLC-QTRAP-MS/MS analysis.

UFLC-QTRAP-MS/MS instrumentation and conditions. The mobile phase of AB Sciex QTRAP-5500 UFLC-MS/MS spectrometry consisted of $0.2 \%$ aqueous formic acid (A) and acetonitrile with $0.2 \%$ formic acid (B). The gradient elution was as follows: 0-5 min: 2\% B; 5-10 min: $2-13 \%$ B; $10-12$ min: $13 \%$ B; $12-17$ min: 13-25\% B; 17-25 min: 25-33\% B; 25-27 min: 33-35\% B; 27-29 min: 35-50\% B; 29-31 min: 50-95\% B. The flow rate was $0.8 \mathrm{~mL} / \mathrm{min}$. Electron spray ionization (ESI) source operates in both ion modes using the multiple reaction monitoring (MRM) transition acquiring the spectra data. Except for lonicerin, kaempferol-3-O-rutinoside can be discriminated from different ion modes; In the same ion mode, isomers with the same ion pairs, therefore, the standard substances of isomer were sequentially injected into QTRAP-MS/MS based on the accurate retention time to identification and quantification. Other conditions are consistent with our previous report ${ }^{29}$.

Method validation and sample determination. The standard solution containing 47 compounds was prepared and the calibration curves were constructed using serially diluted standards. The LODs and LOQs of compounds were defined as signal-to-noise $(\mathrm{S} / \mathrm{N})$ ratios of 3:1 and 10:1, respectively. Method precision was calculated as the RSD of compound concentrations determined by inter-day precision. Moreover, repeatability was achieved by evaluating the closeness of a set of analytical results, which were obtained for six different rep- 


\begin{tabular}{|l|l|l|l|l|l|l|}
\hline Treatment $(\mathbf{m M ~ N a C l})$ & Plant Height $\mathbf{( c m )}$ & Leaf diameter $(\mathbf{c m})$ & Flower buds length $(\mathbf{c m})$ & $\begin{array}{l}\text { Fresh weight of per 100 } \\
\text { flower buds }(\mathbf{g})\end{array}$ & $\begin{array}{l}\text { Dry weight of per 100 } \\
\text { flower buds }(\mathbf{g})\end{array}$ & $\begin{array}{l}\text { Degree of salt stress } \\
\text { injury }\end{array}$ \\
\hline 0 & $144.5 \pm 4.57 \mathrm{a}$ & $6.5 \pm 1.09 \mathrm{a}$ & $5.3 \pm 0.82 \mathrm{a}$ & $15.2 \pm 0.37 \mathrm{a}$ & $9.86 \pm 0.30 \mathrm{a}$ & 0 \\
\hline 100 & $142.0 \pm 2.50 \mathrm{a}$ & $6.4 \pm 0.39 \mathrm{a}$ & $5.6 \pm 0.54 \mathrm{a}$ & $16.4 \pm 1.03 \mathrm{a}$ & $10.16 \pm 0.35 \mathrm{a}$ & 1 \\
\hline 200 & $124.0 \pm 2.94 \mathrm{~b}$ & $6.0 \pm 0.25 \mathrm{~b}$ & $4.1 \pm 0.42 \mathrm{~b}$ & $13.6 \pm 0.89 \mathrm{~b}$ & $8.70 \pm 0.46 \mathrm{~b}$ & 3 \\
\hline 300 & $103.0 \pm 3.21 \mathrm{c}$ & $5.9 \pm 0.10 \mathrm{~b}$ & $3.8 \pm 0.14 \mathrm{~b}$ & $11.8 \pm 1.05 \mathrm{c}$ & $7.91 \pm 0.17 \mathrm{~b}$ & 4 \\
\hline
\end{tabular}

Table 1. Changes in growth parameters of L. japonica under different levels of salt stress (the means \pm SD, $n=3)$.

licate samples from the same sample and expressed in terms of the RSD for those measurements. The stability was measured by analyzing the variations at $0,2,4,8,12$, and $24 \mathrm{~h}$, respectively. At last, the recovery test was performed to check the accuracy of the method. The quantitative determination of the metabolites of LJF under salt stress was performed using the optimal condition by UFLC-QTRAP-MS/MS.

Data processing. The data of UFLC-MS/MS were acquired and analyzed by Analyst 1.6 .6 software (https ://sciex.com/content/SCIEX/na/us/en/products/software/analyst-software.html). The mean values and standard deviation were calculated from the measurements of five replicates. The PLS-DA was made by SIMCA-P 13.0 (https://www.sartorius.com/en/products/process-analytical-technology/data-analytics-software/mvdasoftware/simca). The heat map was made by the software of Heml 1.0 Heatmap Illustrator (http://www1.heatm apper.ca/expression/). One-way ANOVA followed by the Student-Newman-Keuls test was used to compare the means with the significance level by IBM SPSS Statistics 22 (https://www.ibm.com/analytics/spss-statistics-softw are). Pearson Correlation Coefficient was also conducted using IBM SPSS Statistics 22 (https://www.ibm.com/ analytics/spss-statistics-software), and then the difference was considered significant at $p<0.05$. The other data were calculated by Origin Pro 9 (https://www.originlab.com/index.aspx?go=Support\&pid=2051).

\section{Results}

Changes in morphology under salt stress. The growth parameters were shown in Table 1 and phenotype profiles of representative L. japonica presented in Fig. S3. Both leaf diameter and plant height decreased with the increasing salinity. Although average flower buds length and fresh/dry weight per 100 flower buds under high salt stress were the lowest compared with the control group, they all increased at low salt stress, indicating that salt stress had a remarkable effect on the growth parameters of L. japonica. According to the description about the grade of salt stress injury to plants, low salt stress led to the minimum damage.

Changes in photosynthetic pigments under salt stress. As shown in Fig. 1, the content of photosynthetic pigments increased firstly and then decreased except carotenoid; but the increments were insignificant. Among them, low salt stress occupied the highest values, indicating that this treatment significantly increased chlorophyll a, chlorophyll b, total chlorophyll, and carotenoids concentration.

Changes in osmolytes, and lipid peroxidation under salt stress. In the experiment, we identified osmolytes including soluble sugars, soluble proteins, and proline; both soluble proteins and proline had higher values under low salt stress (Fig. 2A,B). The contents of proline also increased compared with the control group. This increase occurred in the early stage of salt stress with low salinity, while with the lasting salinity increase, the proline concentration showed the opposite trend. It is well acknowledged that the content of MDA was quantified as the estimate of membrane lipid peroxidation, which represented the degree of cell membrane damage. As shown in Fig. 2C, MDA continued to accumulate when salinity increases from 100 to $300 \mathrm{mM}$. This phenomenon indicated that L. japonica tolerated salinity, and the oxidative damage peaked under $300 \mathrm{mM}$ salt stress. Amino acids can provide the material basis for normal growth, metabolism, and life support. It can be seen from Fig. 2D that the content of total amino acids reached the maximum $43.31 \mu \mathrm{mol} / \mathrm{mgprot}$, and then almost straight down.

Changes in antioxidant enzyme activity under salt stress. Results from Fig. 3 showed that the activity of POD, SOD, CAT, and APX varied with different concentrations of $\mathrm{NaCl}$ which peaked at $100 \mathrm{mM} \mathrm{NaCl}$ treatment. POD activity peaked at $61.68 \mathrm{U} / \mathrm{mg}$, but suddenly declined by 2.98 -fold from 100 to $300 \mathrm{mM}$. CAT activity induced by 3.2 -fold at $100 \mathrm{mM}$ compared with controls. And APX activity peaked at $1.26 \mathrm{U} / \mathrm{mg}$ firstly, then declined by 7.38-fold compared with controls which accompanied with increasing salinity from 100 to $300 \mathrm{mM}$.

Optimization of UFLC-QTRAP-MS/MS conditions. The optimum UFLC-QTRAP-MS/MS conditions were modified based on our previous work ${ }^{29}$. The most abundant and specific fragment ions were selected as MRM transition from MS/MS and the detailed information of 47 compounds was summarized in (Table S2). The representative extract ion chromatograms of 47 active constituents in the MRM mode were shown in Fig. 4A; the total ion chromatograms (TIC) were presented in Fig. 4B. 


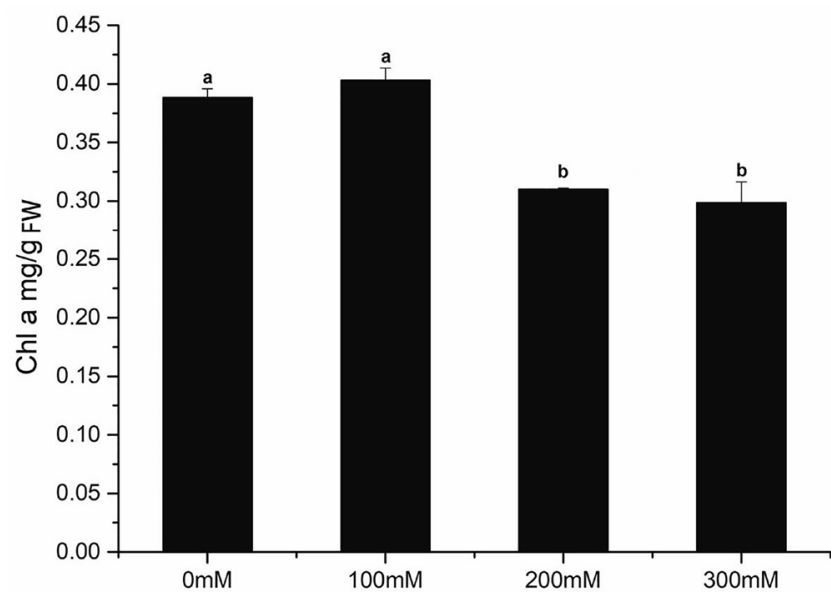

A

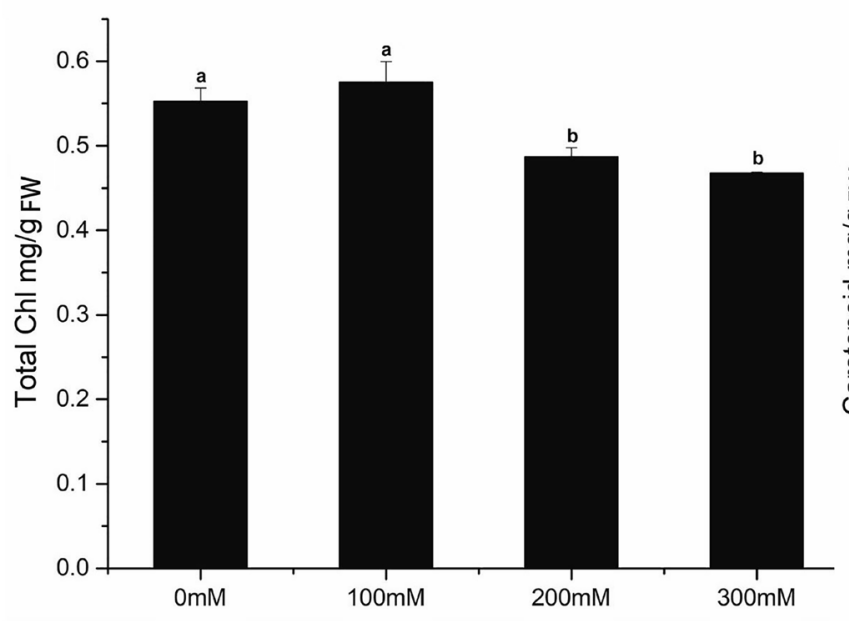

C

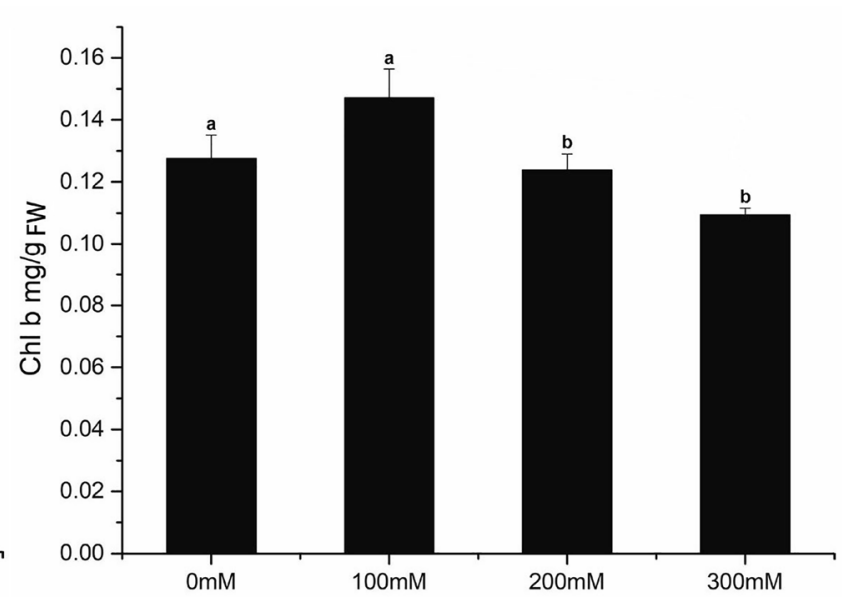

B

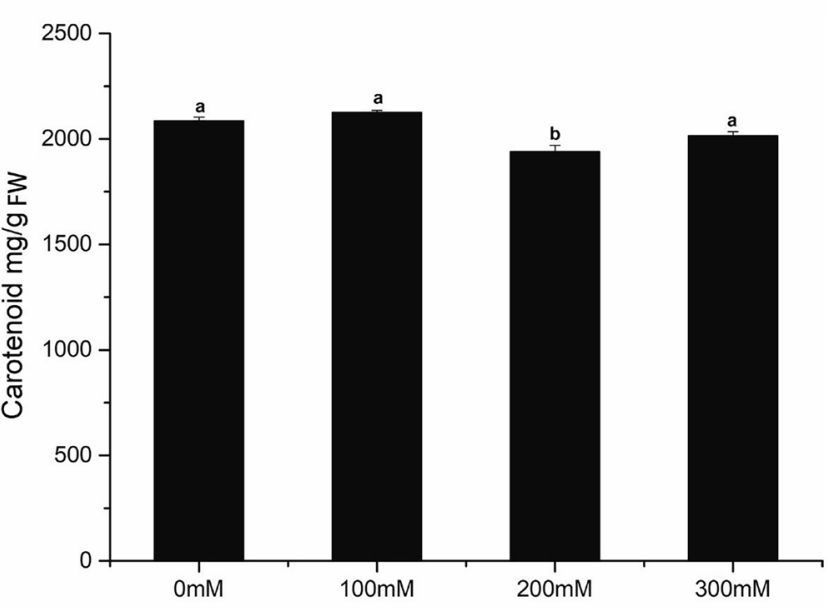

D

Figure 1. Changes in Photosynthetic Pigments contents under different $\mathrm{NaCl}$ concentrations. Chlorophyll a (A), Chlorophyll b (B), Total chlorophyll (C), Carotenoid (D) (The bars were standard deviation (SD) in figure).

Method validation. The detailed information of the method validation for UFLC-QTRAP-MS/MS was listed in Table 2. All of the compounds showed good linearity with $r>0.9990$. The LODs and LOQs of 47 constituents ranged from $0.002-167.42,0.008-552.48 \mathrm{ng} / \mathrm{mL}$, respectively. The RSD values of precision, repeatability, stability of 47 constituents were less than 5\%. The recoveries were measured in the range of $94.2-105.2 \%$.

The accumulation of bioactive constituents of all groups in LJF. The detailed changes of bioactive constituents during 35 days in LJF were obtained. According to Table S3 and Fig. 5, the variation trends of amino acids, nucleosides, organic acids, and flavonoids increased and then decreased. Conversely, iridoids concentration peaked under $300 \mathrm{mM}$, such as loganin secoxyloganin and morroniside increased 3.98, 3.10, and 9-folds compared to controls, respectively. The contents of chlorogenic acid and its derivatives were also enhanced under salt stress, including isochlorogenic A and B were elevated 2.32 and 2.31-folds, respectively. Among them, the trends of chlorogenic acid, neochlorogenic acid, isochlorogenic A, and isochlorogenic B were accordant, which indicated that the accumulation and changes of pathway-related constituents interacted with each other. From the chemical fingerprint and the content data, the chemical fingerprint was similar, but the content of individual constituents or total contents was different under different salt stress. The contents of organic acids were the most abundant under different salt stress. And the total LJF biomass reached a peak by 1.1-fold after 35 days under low salt stress compared with controls. Altogether, we found that the environment had an obvious effect on the accumulation of bioactive constituents, the accumulation of active constituents was the highest under low salt stress.

Dynamic accumulation of multiple bioactive constituents. As shown in Fig. 6, although the accumulation of bioactive constituents under four salinity levels increased with time (20,25, and 35 days, respectively), the dynamic accumulation of these constituents still exhibited some differences. As the accumulation of bioactive constituents peaked at $100 \mathrm{mM}$, we supposed that low salt stress might be the optimum condition 

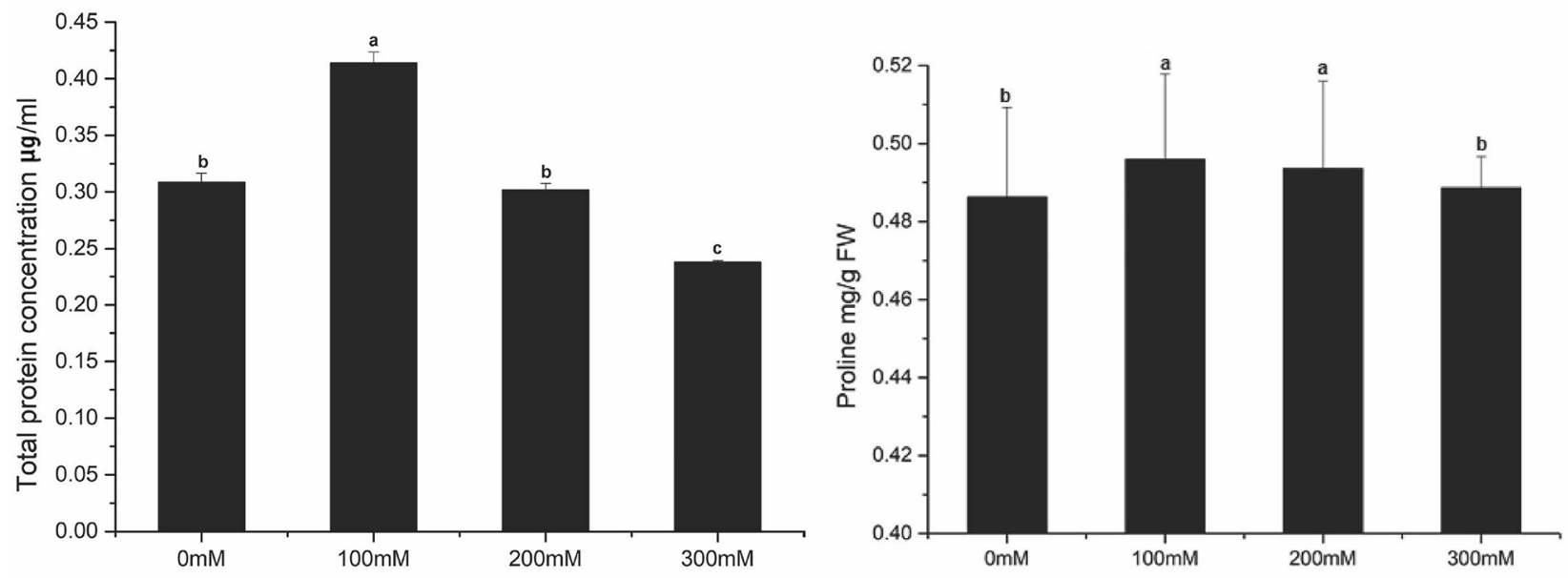

A

B
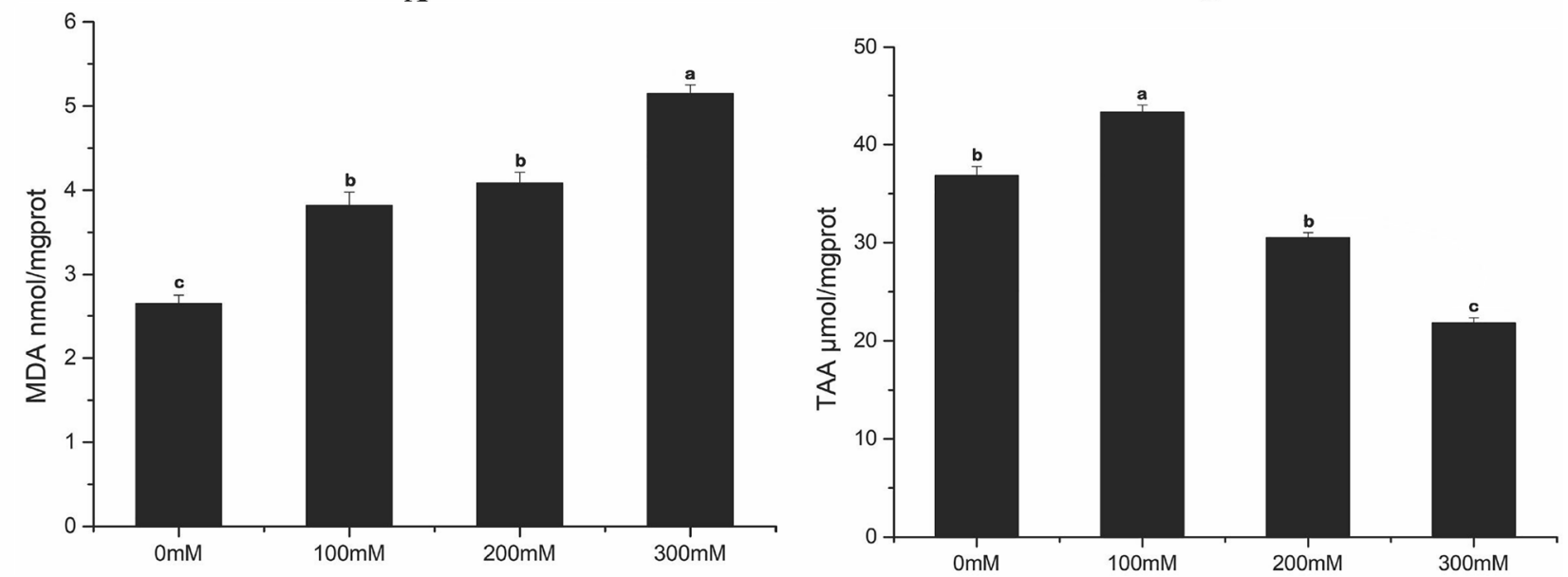

C

D

Figure 2. Changes in soluble proteins (A), proline (B), MDA (C), and TAA (D) under different concentrations of $\mathrm{NaCl}$ (The bars were standard deviation (SD) in figure).

for accumulating bioactive constituents of LJF, which represented the highest medicinal. As one of the indicator constituents to evaluate the quality of LJF, the dynamic accumulation and changing trend of chlorogenic acid was firstly increased and then decreased in the whole process. And the incremental accumulation became greater with time prolonging under $100 \mathrm{mM}$ treatment. This also suggested that the environment has a great impact on the accumulation of active constituents and the different accumulation patterns were presented in the four different salt stress levels. In the long run, low salt stress $(100 \mathrm{mM})$ instead of high salt stress $(300 \mathrm{mM})$ was beneficial for biomass accumulation and growth of LJF.

According to the traditional viewpoint, phenolic constituents were regarded as secondary antioxidants and played a vigorous role in detoxifying ROS. In this study, we found that soil salinity considerably affected phenolic acid contents and antioxidant activity. In Fig. 7, the contents of phenolic acids were positively correlated with antioxidant enzymes activity (SOD, POD, CAT, and APX activity) under salt stress, which were decreased with the reducing phenolic acid contents from 100 to $300 \mathrm{mM}$, indicating that the phenolic acids positively correlated with oxidative damage reduction. Pearson Correlation Coefficient ( $r$ ) was performed to further analyzed the correlations between phenolic acid contents and antioxidant enzymes under salt stress. the results showed that the r-value of SOD, POD, CAT, and APX activity were 0.994, 0.989, 0.532, and 0.416, respectively. Among them, the correlation between phenolic acid contents and SOD, POD activity was significant correlation at $0.01,0.05$ level, respectively.

Multivariate statistical analysis. The hierarchical clustering heat map displayed the changes in the accumulation of 47 constituents under different salt stresses. As shown in Fig. 8A, the changes of 47 constituents in LJF indicated that the environment influenced the accumulation of bioactive constituents. And the specific cases in the control group and salt stress groups were separated. In the different salt stress groups, $100 \mathrm{mM}$ and $200 \mathrm{mM}$ group were firstly clustered together and then separated. Finally, the four different salt stress groups were completely separated. 

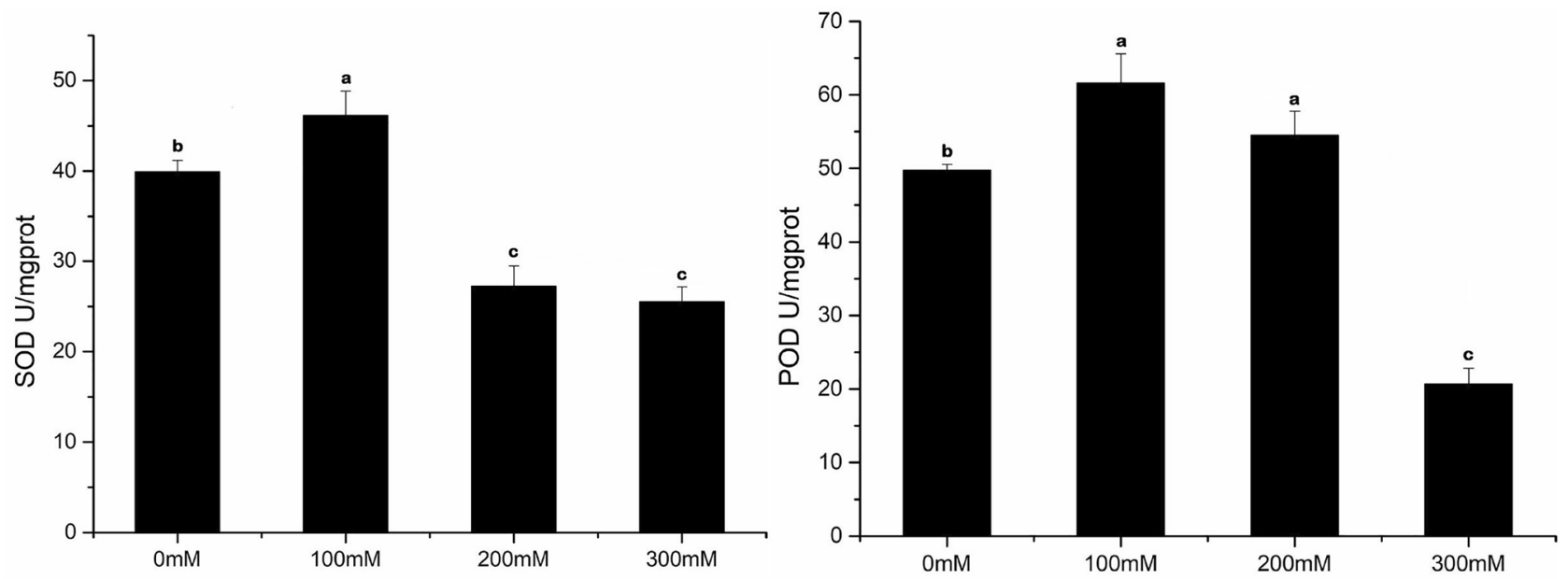

A

B
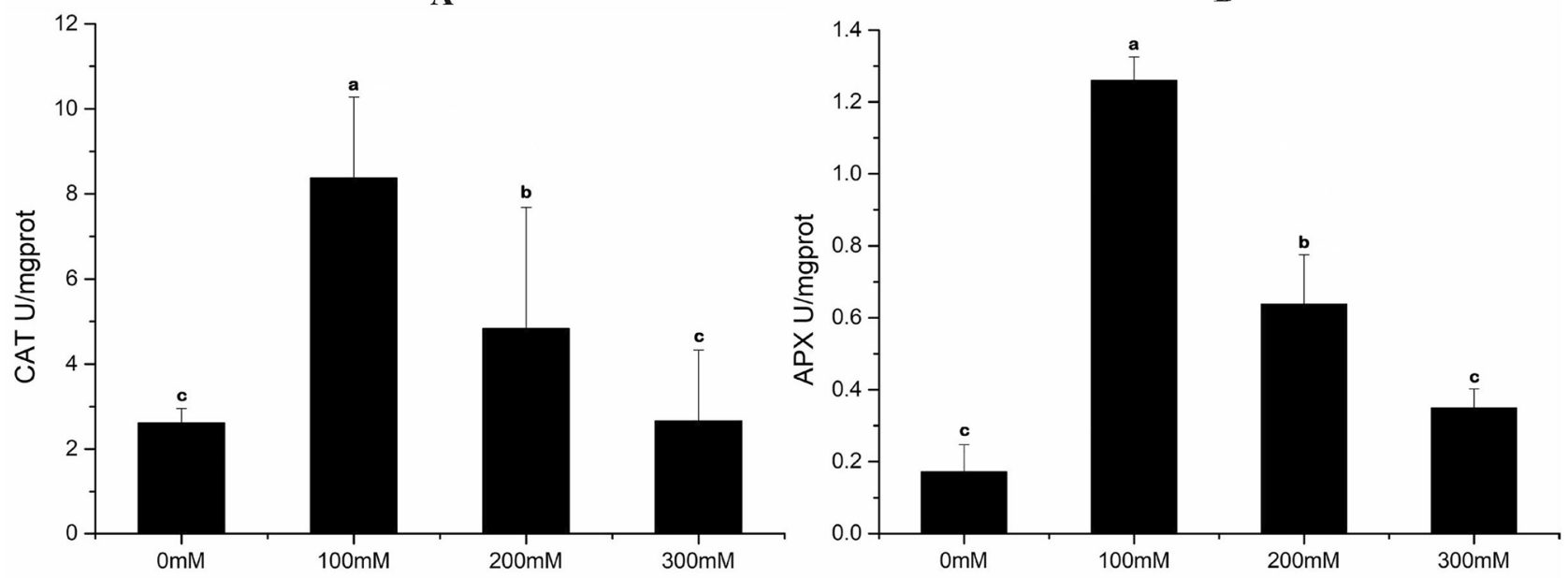

C

D

Figure 3. Changes in superoxide dismutase (SOD, A), peroxidase (POD, B), catalase (CAT, C), ascorbate peroxidase (APX, D) activity under different concentrations of $\mathrm{NaCl}$ (The bars were standard deviation (SD) in figure).

The PLS-DA was performed to cluster and classify LJF under different salt stresses. Samples were divided into four groups with $R^{2} X=0.959, R^{2} Y=0.974$, and $Q^{2}=0.871$, respectively (Fig. 8B); of which the values represented excellent fitness $\left(R^{2} X / R^{2} Y\right)$ and high predictive ability $\left(Q^{2}\right)$. And in the PLS-DA loading plot (Fig. 8C), L-glutamate, L-lysine, neochlorogenic acid, sweroside, loganin acid, secologanic acid, and secoxyloganin possessed great loading values of ions, enhancing to separate samples.

Due to GRA prefers to deal with complex relationship problems with multiple factors and variables like traditional Chinese medicine, it was carried out to evaluate the quality of LJF based on the contents of 47 bioactive constituents. Grey comprehensive evaluation values ( $r i$ ) and quality ranking were listed in Table 3, it showed that the quality ranking of LJF was $100 \mathrm{mM}$ at the top, followed by 0,200 , and $300 \mathrm{mM}$; and the ri values were $0.75,0.52,0.29$, and 0.25 , respectively. It manifested LJF could be grown in soil with $100 \mathrm{mM} \mathrm{NaCl}$ and obtained the optimum quality.

\section{Discussion}

The changes in morphology, physiology, and metabolites of medicinal plants are adaptors to adversity and provide a self-protection mechanism. Salinity has become a worldwide problem that serves as ubiquitous abiotic stress affecting the growth, quality, and yield of medicinal plants. When plants suffer from salt stress, the absorption, accumulation, and distribution of water and nutrients are affected, triggering morphological changes of plants, this is a visual change ${ }^{31}$. Growth parameters and biomass are the most direct indicators of salt tolerance, and then plant height and fresh weight can reflect the biomass of plants ${ }^{32}$. According to these issues, it is inferred that flower buds treated with $100 \mathrm{mM} \mathrm{NaCl}$ might be the maximum accumulation of biomass. The decrease at 200 and $300 \mathrm{mM} \mathrm{NaCl}$ might be due to the injury caused by osmotic stress, and ion toxicity caused by the accumulation of $\mathrm{Na}^{+}$ions, which hinder absorption of $\mathrm{K}^{+}$ions ${ }^{33}$. Therefore, we think that different salt stresses had different influences on the process of growth and development. 


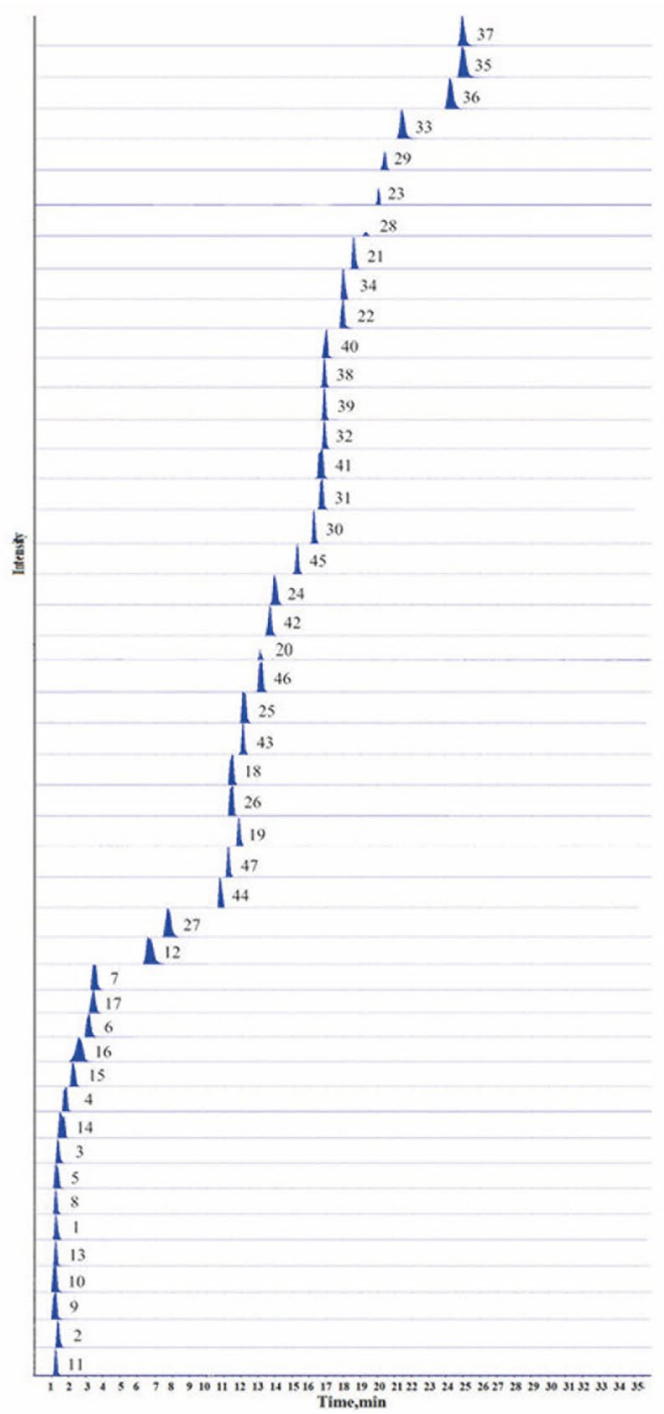

A

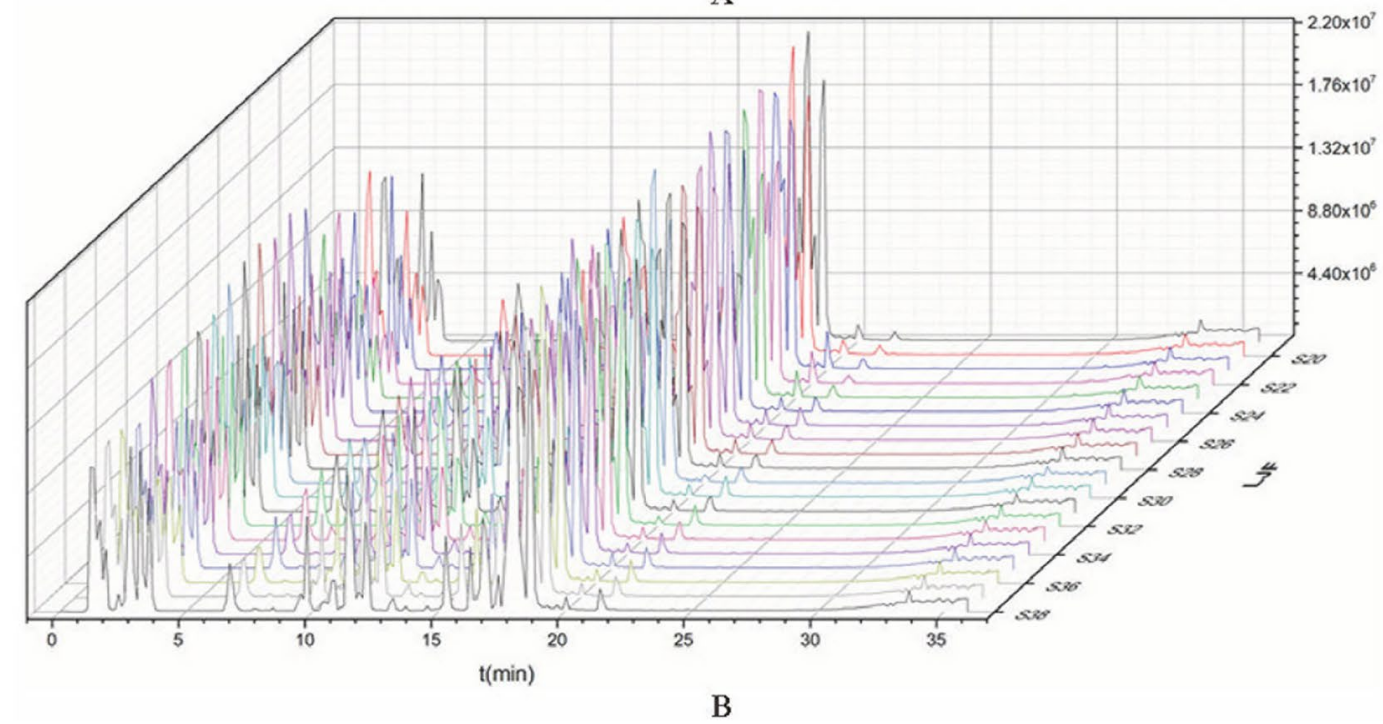

Figure 4. Multiple Reaction Monitoring (MRM) of 47 compounds in LJF (A); Overlay chart of extracted ion chromatograms (EICs) of LJF (B). 


\begin{tabular}{|c|c|c|c|c|c|c|c|c|c|c|c|c|c|}
\hline \multirow[b]{2}{*}{ Number } & \multirow[b]{2}{*}{ Name } & \multirow[b]{2}{*}{ CAS no } & \multirow[b]{2}{*}{ Formula } & \multirow[b]{2}{*}{$\begin{array}{l}\text { Regression } \\
\text { equation }\end{array}$} & \multirow[b]{2}{*}{$r$} & \multirow{2}{*}{$\begin{array}{l}\text { Linear } \\
\text { range } \\
(\mathbf{n g} / \\
\mathrm{mL})\end{array}$} & \multirow[b]{2}{*}{$\begin{array}{l}\operatorname{LOD}(\mathbf{n g} / \\
\mathrm{ml})\end{array}$} & \multirow[b]{2}{*}{$\begin{array}{l}\text { LOQ(ng/ } \\
\mathrm{ml})\end{array}$} & \multirow[b]{2}{*}{$\begin{array}{l}\text { Precision } \\
\text { (RSD\%; } \\
n=6 \text { ) }\end{array}$} & \multirow{2}{*}{$\begin{array}{l}\text { Repeatability } \\
(\text { RSD\%; } n=6)\end{array}$} & \multirow{2}{*}{\begin{tabular}{|l|} 
Stability \\
$\begin{array}{l}\text { (RSD\%; } \\
n=6 ;)\end{array}$ \\
\end{tabular}} & \multicolumn{2}{|c|}{ Recovery } \\
\hline & & & & & & & & & & & & Mean & RSD\% \\
\hline 1 & L-Alanine & $56-41-7$ & $\mathrm{C}_{3} \mathrm{H}_{7} \mathrm{NO}_{2}$ & $y=4.36 \mathrm{E}^{4}+1.1 \mathrm{E} 3 x$ & 0.9995 & \begin{tabular}{|l|}
$2.06-$ \\
25,800
\end{tabular} & 0.052 & 0.194 & 1.65 & 2.47 & 4.32 & 100.08 & 4.56 \\
\hline 2 & L-Serine & $56-45-1$ & $\mathrm{C}_{3} \mathrm{H}_{7} \mathrm{NO}_{3}$ & $y=6.13 \mathrm{E}^{4}+3.07 \mathrm{E}^{3} x$ & 0.9996 & \begin{tabular}{|l|}
$1.04-$ \\
12,550 \\
\end{tabular} & 0.100 & 0.347 & 1.87 & 3.73 & 1.72 & 99.56 & 1.98 \\
\hline 3 & L-Proline & $147-85-3$ & $\mathrm{C}_{5} \mathrm{H}_{9} \mathrm{NO}_{2}$ & $y=2.28 \mathrm{E}^{5}+1.17 \mathrm{E}^{4} x$ & 0.9996 & \begin{tabular}{|l|}
$5.25-$ \\
13,125 \\
\end{tabular} & 0.053 & 0.210 & 1.80 & 4.23 & 3.63 & 101.36 & 2.39 \\
\hline 4 & L-Valine & $72-18-4$ & $\mathrm{C}_{5} \mathrm{H}_{11} \mathrm{NO}_{2}$ & $y=1.28 \mathrm{E}^{5}+4.95 \mathrm{E}^{3} x$ & 0.9999 & $\begin{array}{l}18.46- \\
46,615\end{array}$ & 0.037 & 0.133 & 3.98 & 3.74 & 4.26 & 98.55 & 3.86 \\
\hline 5 & L-Threonine & $72-19-5$ & $\mathrm{C}_{4} \mathrm{H}_{9} \mathrm{NO}_{3}$ & $y=8.23 \mathrm{E}^{3}+384 x$ & 0.9992 & $\begin{array}{l}4.024- \\
40,240\end{array}$ & 0.008 & 0.029 & 3.00 & 4.16 & 4.29 & 96.76 & 4.18 \\
\hline 6 & L-Isoleucine & $73-32-5$ & $\mathrm{C}_{6} \mathrm{H}_{13} \mathrm{NO}_{2}$ & $y=2.97 \mathrm{E}^{5}+1.5 \mathrm{E}^{4} x$ & 0.999 & $\begin{array}{l}1.22- \\
15,210\end{array}$ & 0.012 & 0.039 & 3.74 & 3.77 & 4.11 & 100.09 & 2.15 \\
\hline 7 & L-Leucine & $61-90-5$ & $\mathrm{C}_{6} \mathrm{H}_{13} \mathrm{NO}_{2}$ & $y=3.23 \mathrm{E}^{5}+2.69 \mathrm{E}^{4} x$ & 0.9995 & \begin{tabular}{|l|}
$1.03-$ \\
12,875
\end{tabular} & 0.010 & 0.033 & 4.50 & 3.98 & 0.37 & 102.97 & 2.06 \\
\hline 8 & L-Aspartic acid & $56-84-8$ & $\mathrm{C}_{4} \mathrm{H}_{7} \mathrm{NO}_{4}$ & $y=1.05 \mathrm{E}^{5}+1.8 \mathrm{E}^{3} x$ & 0.9998 & $\begin{array}{l}5.03- \\
25,152\end{array}$ & 0.050 & 0.161 & 3.19 & 2.94 & 3.05 & 99.27 & 2.96 \\
\hline 9 & L-Glutamate & $138-18-1$ & $\mathrm{C}_{5} \mathrm{H}_{7} \mathrm{NO}_{4}$ & $y=4.8 \mathrm{E}^{4}+554 x$ & 0.9995 & \begin{tabular}{|l|}
$10.32-$ \\
129,030
\end{tabular} & 0.103 & 0.310 & 4.26 & 4.81 & 3.05 & 96.93 & 3.96 \\
\hline 10 & L-Lysine & $56-87-1$ & $\mathrm{C}_{6} \mathrm{H}_{14} \mathrm{~N}_{2} \mathrm{O}_{2}$ & $y=7.67 \mathrm{E}^{4}+773 x$ & 0.9991 & \begin{tabular}{|l|}
$9.11-$ \\
113,960 \\
\end{tabular} & 0.091 & 0.274 & 3.26 & 3.65 & 2.62 & 95.67 & 3.73 \\
\hline 11 & L-Histidine & 71-00-1 & $\mathrm{C}_{6} \mathrm{H}_{9} \mathrm{~N}_{3} \mathrm{O}_{2}$ & $y=3.48 \mathrm{E}^{3}-6.58 \mathrm{E}^{3} x$ & 0.9999 & \begin{tabular}{|l|}
$2.12-$ \\
8,512
\end{tabular} & 0.004 & 0.015 & 0.47 & 2.94 & 2.34 & 105.2 & 4.64 \\
\hline 12 & L-Phenylalanine & $63-91-2$ & $\mathrm{C}_{9} \mathrm{H}_{11} \mathrm{NO}_{2}$ & $y=3.21 \mathrm{E}^{5}+1.94 \mathrm{E}^{4} x$ & 0.9992 & $\begin{array}{l}1.09- \\
13,650\end{array}$ & 0.011 & 0.033 & 1.16 & 3.01 & 1.87 & 97.56 & 3.06 \\
\hline 13 & L-Arginine & $74-79-3$ & $\mathrm{C}_{6} \mathrm{H}_{14} \mathrm{~N}_{4} \mathrm{O}_{2}$ & $y=2.55 \mathrm{E}^{4}+1.49 \mathrm{E}^{3} x$ & 0.9997 & \begin{tabular}{|l|}
$6.87-$ \\
34,340 \\
\end{tabular} & 0.172 & 0.515 & 2.82 & 1.32 & 9.83 & 100.17 & 1.98 \\
\hline 14 & Cytidine & $65-46-3$ & $\mathrm{C}_{9} \mathrm{H}_{13} \mathrm{~N}_{3} \mathrm{O}_{5}$ & $y=2.51 \mathrm{E}^{3}+7.17 \mathrm{E}^{3} x$ & 1 & $\begin{array}{l}0.2224- \\
11,120\end{array}$ & 0.056 & 0.167 & 1.84 & 2.61 & 3.41 & 94.2 & 3.9 \\
\hline 15 & Uridine & $58-96-8$ & $\mathrm{C}_{9} \mathrm{H}_{12} \mathrm{~N}_{2} \mathrm{O}_{6}$ & $y=2.15 \mathrm{E}^{3}+1.44 \mathrm{E}^{3} x$ & 0.9990 & \begin{tabular}{|l|}
$1.72-$ \\
21,520 \\
\end{tabular} & 0.043 & 0.129 & 2.57 & 4.60 & 3.41 & 100.95 & 2.55 \\
\hline 16 & Adenosine & $58-61-7$ & $\mathrm{C}_{10} \mathrm{H}_{13} \mathrm{~N}_{5} \mathrm{O}_{4}$ & $y=13.53 \mathrm{E}^{4}+.35 \mathrm{E}^{4} x$ & 0.9990 & \begin{tabular}{|l|}
$0.21-$ \\
2,580
\end{tabular} & 0.002 & 0.008 & 4.10 & 2.56 & 1.99 & 97.76 & 3.7 \\
\hline 17 & Inosine & $58-63-9$ & $\mathrm{C}_{10} \mathrm{H}_{12} \mathrm{~N}_{4} \mathrm{O}_{5}$ & $y=1.32 \mathrm{E}^{5}+2.78 \mathrm{E}^{4} x$ & 0.9997 & $\begin{array}{l}2.47- \\
6,180\end{array}$ & 0.124 & 0.492 & 3.55 & 1.35 & 3.13 & 101.58 & 4.12 \\
\hline 18 & Chlorogenic acid & $327-97-9$ & $\mathrm{C}_{16} \mathrm{H}_{18} \mathrm{O}_{9}$ & $y=5.46 \mathrm{E}^{5}+5.05 \mathrm{E}^{3} x$ & 0.9992 & $\begin{array}{l}24.48- \\
10,100\end{array}$ & 1.224 & 4.039 & 3.30 & 2.65 & 4.87 & 99.77 & 1.22 \\
\hline 19 & Neochlorogenic acid & $906-33-2$ & $\mathrm{C}_{16} \mathrm{H}_{18} \mathrm{O}_{9}$ & $y=4.17 \mathrm{E}^{5}+243 x$ & 0.9995 & \begin{tabular}{|l}
$837.08-$ \\
88,375
\end{tabular} & 167.418 & 552.478 & 4.82 & 4.34 & 4.02 & 96.7 & 3.97 \\
\hline 20 & Cryptochlorogenic acid & $905-99-7$ & $\mathrm{C}_{16} \mathrm{H}_{18} \mathrm{O}_{9}$ & $y=6.54 \mathrm{E}^{5}+1.17 \mathrm{E}^{4} x$ & 0.9993 & $\begin{array}{l}527.5- \\
41,800\end{array}$ & 105.500 & 316.500 & 1.70 & 2.33 & 3.67 & 100.66 & 1.62 \\
\hline 21 & Isochlorogenic A & \begin{tabular}{|l|}
$2450-$ \\
$53-5$
\end{tabular} & $\mathrm{C}_{25} \mathrm{H}_{24} \mathrm{O}_{12}$ & $y=8.34 \mathrm{E}^{5}+5.81 \mathrm{E}^{3} x$ & 0.9990 & $\begin{array}{l}31.64- \\
92,250 \\
\end{array}$ & 0.633 & 2.278 & 2.02 & 1.87 & 3.23 & 98.7 & 2.65 \\
\hline 22 & Isochlorogenic B & $\begin{array}{l}14,534- \\
61-3\end{array}$ & $\mathrm{C}_{25} \mathrm{H}_{24} \mathrm{O}_{12}$ & $y=5.95 \mathrm{E}^{5}+4.88 \mathrm{E}^{3} x$ & 0.9998 & $\begin{array}{l}36.96- \\
227,900\end{array}$ & 7.392 & 24.394 & 5.00 & 2.09 & 2.36 & 100.67 & 3.65 \\
\hline 23 & Isochlorogenic $\mathrm{C}$ & $\begin{array}{l}57,378- \\
72-0\end{array}$ & $\mathrm{C}_{25} \mathrm{H}_{24} \mathrm{O}_{12}$ & $y=2.84 \mathrm{E}^{5}+8.24 \mathrm{E}^{4} x$ & 0.9996 & $\begin{array}{l}3.21- \\
59,400\end{array}$ & 0.032 & 0.125 & 1.31 & 3.48 & 1.83 & 99.4 & 2.05 \\
\hline 24 & $\begin{array}{l}\text { 1,3-O-dicaffeoylquinic } \\
\text { acid }\end{array}$ & \begin{tabular}{|l|}
$19,870-$ \\
$46-3$ \\
\end{tabular} & $\mathrm{C}_{25} \mathrm{H}_{24} \mathrm{O}_{12}$ & $y=5.21 \mathrm{E}^{5}+2.03 \mathrm{E}^{4} x$ & 0.9994 & $\begin{array}{l}119.9- \\
24,480 \\
\end{array}$ & 23.980 & 71.940 & 1.57 & 2.26 & 1.65 & 100.95 & 3.46 \\
\hline 25 & Caffeic acid & $331-39-5$ & $\mathrm{C}_{9} \mathrm{H}_{8} \mathrm{O}_{4}$ & $y=9.74 \mathrm{E}^{4}+5.23 \mathrm{E}^{3} x$ & 0.9996 & $\begin{array}{l}110.5- \\
24,840\end{array}$ & 22.100 & 77.350 & 1.02 & 1.61 & 2.35 & 101.96 & 2.12 \\
\hline 26 & Quinic acid & $77-95-2$ & $\mathrm{C}_{7} \mathrm{H}_{12} \mathrm{O}_{6}$ & $y=1.06 \mathrm{E}^{5}+281 x$ & 0.9996 & $\begin{array}{l}11.05- \\
24,192\end{array}$ & 0.685 & 2.192 & 3.90 & 2.64 & 2.35 & 100.92 & 2.28 \\
\hline 27 & Protocatechuic acid & $99-50-3$ & $\mathrm{C}_{7} \mathrm{H}_{6} \mathrm{O}_{4}$ & $y=5.71 \mathrm{E}^{4}+1.88 \mathrm{E}^{4} x$ & 0.9991 & \begin{tabular}{|l|}
$6.85-$ \\
25,665 \\
\end{tabular} & 1.100 & 3.630 & 1.95 & 2.35 & 3.39 & 99.65 & 2.8 \\
\hline 28 & Ferulic acid & $\begin{array}{l}1135- \\
24-6\end{array}$ & $\mathrm{C}_{10} \mathrm{H}_{10} \mathrm{O}_{4}$ & $y=2.33 \mathrm{E}^{3}-101 x$ & 0.9999 & \begin{tabular}{|l|}
$3.65-$ \\
16,150 \\
\end{tabular} & 0.866 & 2.858 & 3.62 & 3.05 & 2.47 & 101.22 & 3.68 \\
\hline 29 & $\begin{array}{l}\text { 4,5-O-dicaffeoylquinic } \\
\text { acid methyl ester }\end{array}$ & \begin{tabular}{|l}
$114,637-$ \\
$83-1$
\end{tabular} & $\mathrm{C}_{26} \mathrm{H}_{26} \mathrm{O}_{12}$ & $y=9.8 \mathrm{E}^{3}+4.59 \mathrm{E}^{3} x$ & 0.9994 & $\begin{array}{l}0.36- \\
96,390 \\
\end{array}$ & 0.018 & 0.072 & 2.04 & 3.11 & 4.47 & 97.98 & 4.48 \\
\hline 30 & Rutin & $153-18-4$ & $\mathrm{C}_{27} \mathrm{H}_{30} \mathrm{O}_{16}$ & $y=1.31 \mathrm{E}^{5}+2.4 \mathrm{E}^{3} x$ & 0.9997 & $\begin{array}{l}4.97- \\
9,432 \\
\end{array}$ & 0.497 & 1.639 & 2.42 & 3.50 & 4.92 & 98.62 & 4.01 \\
\hline 31 & Hyperoside & $482-36-0$ & $\mathrm{C}_{21} \mathrm{H}_{20} \mathrm{O}_{12}$ & $y=9.41 \mathrm{E}^{4}+1.11 \mathrm{E}^{4} \mathrm{x}$ & 0.9999 & $\begin{array}{l}14.21- \\
16,950 \\
\end{array}$ & 0.711 & 2.132 & 0.39 & 1.94 & 2.41 & 99.85 & 3.82 \\
\hline 32 & Luteoloside & \begin{tabular}{|l}
$5373-$ \\
$11-5$
\end{tabular} & $\mathrm{C}_{21} \mathrm{H}_{20} \mathrm{O}_{11}$ & $y=1.02 \mathrm{E}^{5}+2.11 \mathrm{E}^{3} x$ & 0.9994 & $\begin{array}{l}0.71- \\
7,537\end{array}$ & 0.081 & 0.322 & 2.11 & 2.02 & 4.36 & 99.56 & 2.95 \\
\hline 33 & Luteolin & $491-70-3$ & $\mathrm{C}_{15} \mathrm{H}_{10} \mathrm{O}_{6}$ & $y=3.21 \mathrm{E}^{5}+5.7 \mathrm{E}^{3} x$ & 0.9994 & \begin{tabular}{|l|}
$25.67-$ \\
8,220
\end{tabular} & 1.283 & 5.116 & 1.68 & 2.25 & 3.43 & 100.89 & 4.25 \\
\hline
\end{tabular}




\begin{tabular}{|c|c|c|c|c|c|c|c|c|c|c|c|c|c|}
\hline \multirow[b]{2}{*}{ Number } & \multirow[b]{2}{*}{ Name } & \multirow[b]{2}{*}{ CAS no } & \multirow[b]{2}{*}{ Formula } & \multirow[b]{2}{*}{$\begin{array}{l}\text { Regression } \\
\text { equation }\end{array}$} & \multirow[b]{2}{*}{$r$} & \multirow{2}{*}{$\begin{array}{l}\begin{array}{l}\text { Linear } \\
\text { range } \\
(\mathrm{ng} /\end{array} \\
\mathrm{mL})\end{array}$} & \multirow[b]{2}{*}{$\begin{array}{l}\operatorname{LOD}(\mathrm{ng} / \\
\mathrm{ml})\end{array}$} & \multirow[b]{2}{*}{$\begin{array}{l}\mathrm{LOQ}(\mathrm{ng} / \\
\mathrm{ml})\end{array}$} & \multirow{2}{*}{$\begin{array}{l}\text { Precision } \\
\text { (RSD\%; } \\
n=6)\end{array}$} & \multirow{2}{*}{$\begin{array}{l}\text { Repeatability } \\
(\mathrm{RSD} \% ; n=6)\end{array}$} & \multirow{2}{*}{\begin{tabular}{|l|} 
Stability \\
(RSD\%; \\
$n=6 ;)$
\end{tabular}} & \multicolumn{2}{|c|}{ Recovery } \\
\hline & & & & & & & & & & & & Mean & RSD\% \\
\hline 34 & Rhoifolin & $\begin{array}{l}17,306- \\
46-6\end{array}$ & $\mathrm{C}_{27} \mathrm{H}_{30} \mathrm{O}_{14}$ & $y=1.95 \mathrm{E}^{3}-6.96 \mathrm{E}^{3} x$ & 0.9995 & $\begin{array}{l}0.17- \\
17,250\end{array}$ & 0.007 & 0.028 & 3.90 & 4.65 & 2.89 & 99.92 & 3.12 \\
\hline 35 & Diosmetin & $520-34-3$ & $\mathrm{C}_{16} \mathrm{H}_{12} \mathrm{O}_{6}$ & $y=2.19 \mathrm{E}^{4}+1.33 \mathrm{E}^{4} x$ & 0.9998 & \begin{tabular}{|l|}
$0.27-$ \\
14,210 \\
\end{tabular} & 0.003 & 0.012 & 1.01 & 3.13 & 2.17 & 100.76 & 3.05 \\
\hline 36 & Apigenin & $520-36-5$ & $\mathrm{C}_{15} \mathrm{H}_{10} \mathrm{O}_{5}$ & $y=1.21 \mathrm{E}^{4}+1.4 \mathrm{E}^{4} x$ & 0.9999 & $\begin{array}{l}0.02- \\
18,000\end{array}$ & 0.002 & 0.008 & 0.70 & 2.79 & 3.54 & 103.29 & 3.58 \\
\hline 37 & Kaempferol & $520-18-3$ & $\mathrm{C}_{15} \mathrm{H}_{10} \mathrm{O}_{6}$ & $y=2.81 \mathrm{E}^{3}+527 x$ & 0.9992 & \begin{tabular}{|l|}
$0.17-$ \\
86,620
\end{tabular} & 0.034 & 0.119 & 0.86 & 4.40 & 1.66 & 101.27 & 3.09 \\
\hline 38 & Astragalin & $480-10-4$ & $\mathrm{C}_{21} \mathrm{H}_{20} \mathrm{O}_{11}$ & $y=3.97 \mathrm{E}^{4}+5.71 \mathrm{E}^{3} x$ & 0.9995 & $\begin{array}{l}0.19- \\
66,00\end{array}$ & 0.038 & 0.132 & 0.72 & 3.57 & 5.48 & 100.87 & 3.77 \\
\hline 39 & Lonicerin & $\begin{array}{l}25,694- \\
72-8\end{array}$ & $\mathrm{C}_{27} \mathrm{H}_{30} \mathrm{O}_{15}$ & $y=1.91 \mathrm{E}^{5}+992 x$ & 0.9998 & $\begin{array}{l}9.64- \\
342,500\end{array}$ & 9.639 & 28.917 & 2.44 & 0.65 & 4.57 & 100.77 & 2.08 \\
\hline 40 & $\begin{array}{l}\text { Kaempferol-3-O- } \\
\text { rutinoside }\end{array}$ & $\begin{array}{l}17,650- \\
84-9\end{array}$ & $\mathrm{C}_{27} \mathrm{H}_{30} \mathrm{O}_{15}$ & $y=3.74 \mathrm{E}^{5}+3.48 \mathrm{E}^{4} x$ & 0.9998 & $\begin{array}{l}2.24- \\
5,610\end{array}$ & 0.022 & 0.074 & 1.50 & 4.72 & 3.12 & 99.68 & 3.16 \\
\hline 41 & Isoquercitrin & $482-35-9$ & $\mathrm{C}_{21} \mathrm{H}_{20} \mathrm{O}_{12}$ & $y=2.74 \mathrm{E}^{5}+7.34 \mathrm{E}^{3} x$ & 0.9996 & $\begin{array}{l}3.23- \\
27,625\end{array}$ & 0.808 & 2.423 & 0.78 & 2.06 & 2.25 & 99.58 & 2.35 \\
\hline 42 & Sweroside & $\begin{array}{l}14,215- \\
86-2\end{array}$ & $\mathrm{C}_{16} \mathrm{H}_{22} \mathrm{O}_{9}$ & $y=4.83 \mathrm{E}^{3}+79.8 x$ & 0.9993 & $\begin{array}{l}4.75- \\
5,995\end{array}$ & 0.475 & 1.426 & 2.39 & 2.03 & 2.55 & 101.78 & 2.95 \\
\hline 43 & Secologanic acid & \begin{tabular}{|l|}
$60,077-$ \\
$46-5$
\end{tabular} & $\mathrm{C}_{16} \mathrm{H}_{22} \mathrm{O}_{10}$ & $y=2.01 \mathrm{E}^{5}+635 x$ & 0.9992 & \begin{tabular}{|l|}
$18.23-$ \\
18,480 \\
\end{tabular} & 1.823 & 6.199 & 1.76 & 3.58 & 3.11 & 99.82 & 4.02 \\
\hline 44 & Loganin acid & \begin{tabular}{|l|}
$22,255-$ \\
$40-9$ \\
\end{tabular} & $\mathrm{C}_{16} \mathrm{H}_{24} \mathrm{O}_{10}$ & $y=1.27 \mathrm{E}^{5}+1.54 \mathrm{E}^{3} x$ & 0.9997 & \begin{tabular}{|l|}
$0.74-$ \\
15,820 \\
\end{tabular} & 0.074 & 0.286 & 4.51 & 4.55 & 4.47 & 103.66 & 3.79 \\
\hline 45 & Loganin & $\begin{array}{l}18,524- \\
94-2\end{array}$ & $\mathrm{C}_{17} \mathrm{H}_{26} \mathrm{O}_{10}$ & $y=1.45 \mathrm{E}^{3}+12.8 x$ & 0.9990 & $\begin{array}{l}2.09- \\
1,605\end{array}$ & 0.084 & 0.324 & 1.28 & 3.68 & 4.95 & 98.78 & 3.14 \\
\hline 46 & Secoxyloganin & \begin{tabular}{|l|}
$58,822-$ \\
$47-2$ \\
\end{tabular} & $\mathrm{C}_{17} \mathrm{H}_{24} \mathrm{O}_{11}$ & $y=1.04 \mathrm{E}^{5}+1.46 \mathrm{E}^{3} x$ & 0.9997 & \begin{tabular}{|l|}
$0.71-$ \\
418,544 \\
\end{tabular} & 0.071 & 0.283 & 1.16 & 3.63 & 3.46 & 100.02 & 2.76 \\
\hline 47 & Morroniside & $\begin{array}{l}25,406- \\
64-8\end{array}$ & $\mathrm{C}_{17} \mathrm{H}_{26} \mathrm{O}_{11}$ & $y=783+324 x$ & 0.9996 & $\begin{array}{l}0.20- \\
105,50\end{array}$ & 0.010 & 0.039 & 3.43 & 4.00 & 3.29 & 100.75 & 4.19 \\
\hline
\end{tabular}

Table 2. Regression equations, limit of detection (LOD), limit of quantification (LOQ), precisions, repeatabilities, stabilities, and recoveries for 47 bioactive components of Lonicerae Japonicae Flos.

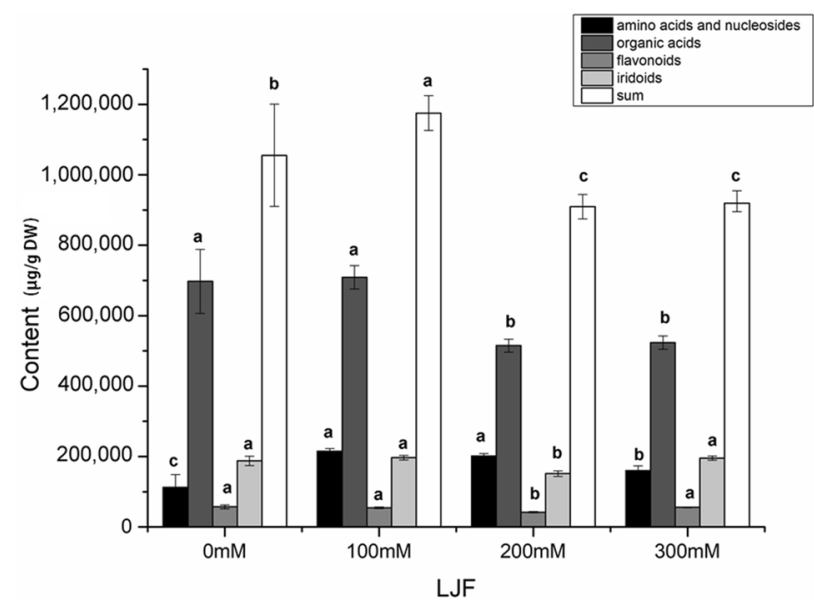

Figure 5. The accumulation of primary and secondary metabolites under salt stress in LJF. Bars are express as the mean $\pm \operatorname{SD}(n=5)$, the letters of bars indicate significant differences at $p<0.05$.

The content of MDA is regarded as a reliable indicator of membranes' oxidative damages and has antioxidant activity through the protection of cellular membranes and enzyme integrity ${ }^{34}$. In this study, the contents of MDA increase with salinity, which indicate salt aggravates oxidative damage of LJF. Proline is an important osmolyte in plants, its accumulation is a defense response to salt stress ${ }^{35}$. Proline not only promotes osmotic homeostasis, but also associated with the salt tolerance of LJF. This is consistent with previous results on wheat ${ }^{36}$, wild chicory ${ }^{37}$. Besides, as a protein precursor, it is the energy source of the stress recovery process ${ }^{38}$. Amino acids and biological enzymes are also primary metabolites of plants and play a role in maintaining osmotic balance ${ }^{39}$. According to the results, total amino acids content and photosynthesis/antioxidant enzyme activity peak at $100 \mathrm{mM}$ salt condition, which is optimal salt concentration. 


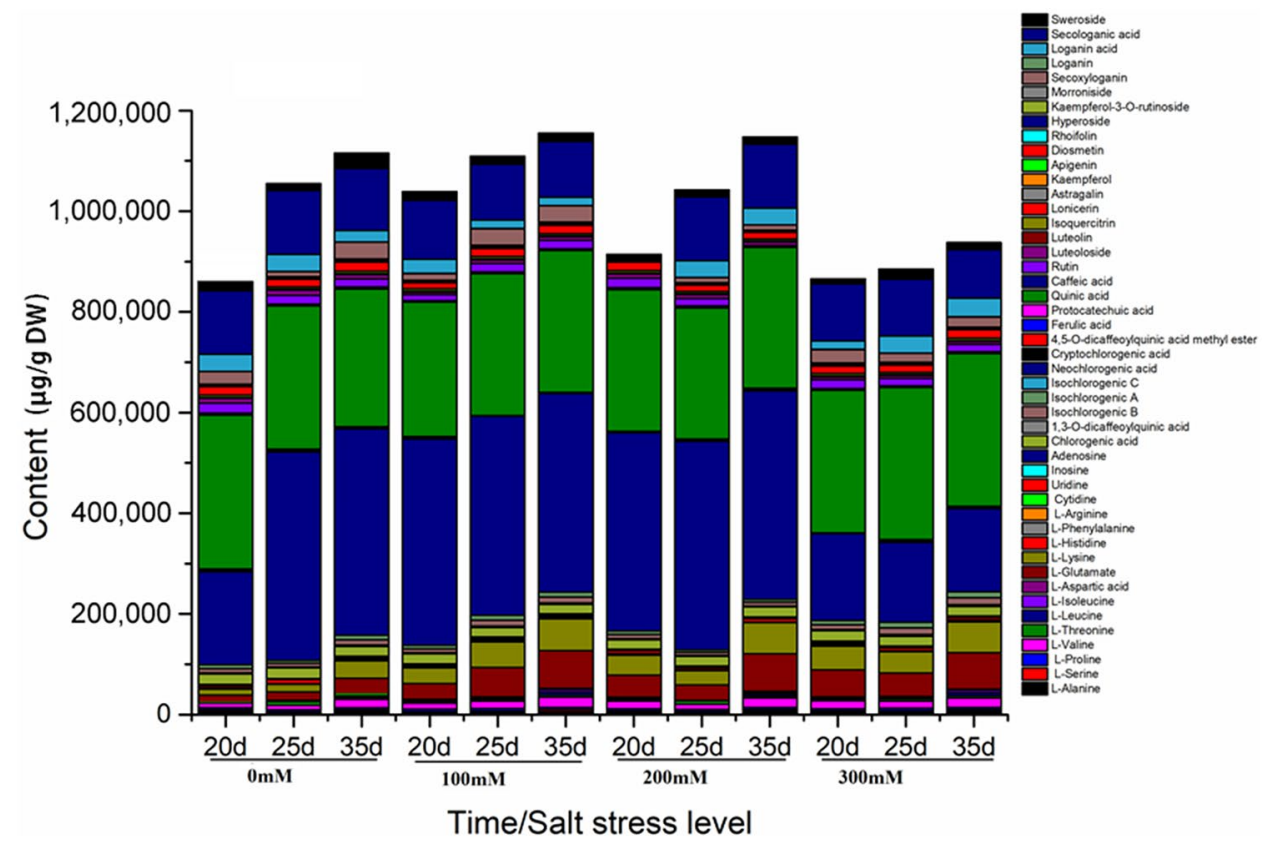

Figure 6. Accumulation contents of 47 compounds in 20, 25, 35 days, respectively.

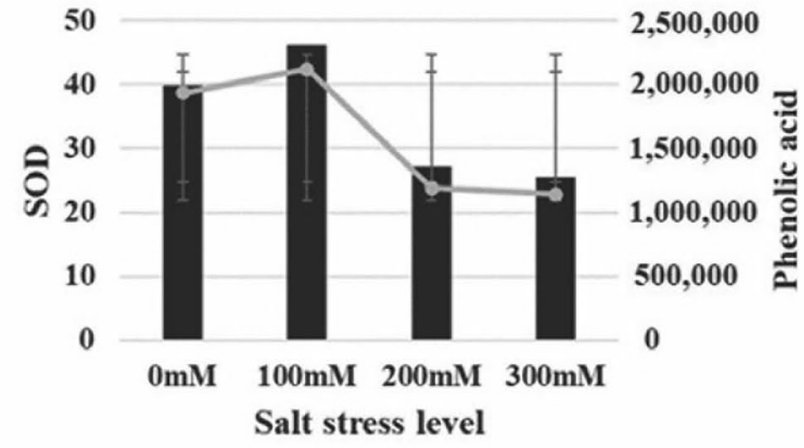

SOD $\rightarrow$ Total phenolic acid contents

A

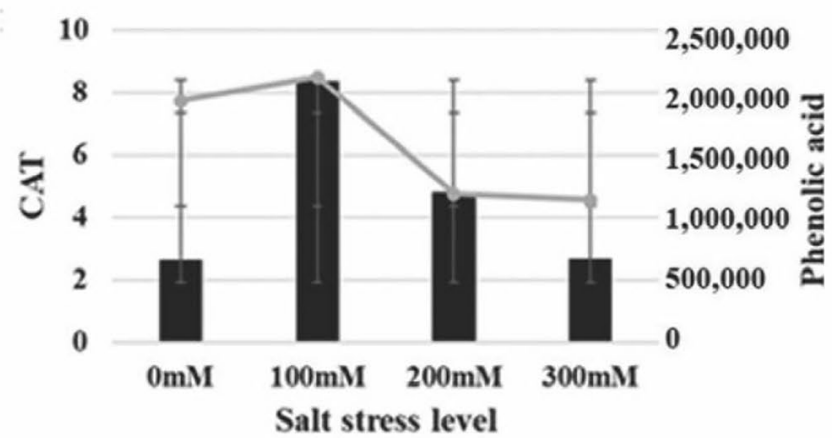

CAT $\leadsto$ Total phenolic acid contents

C

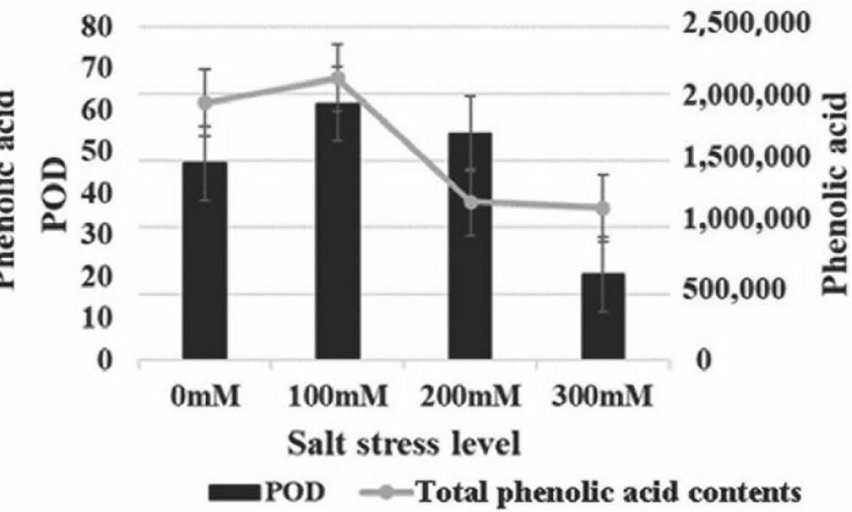

B

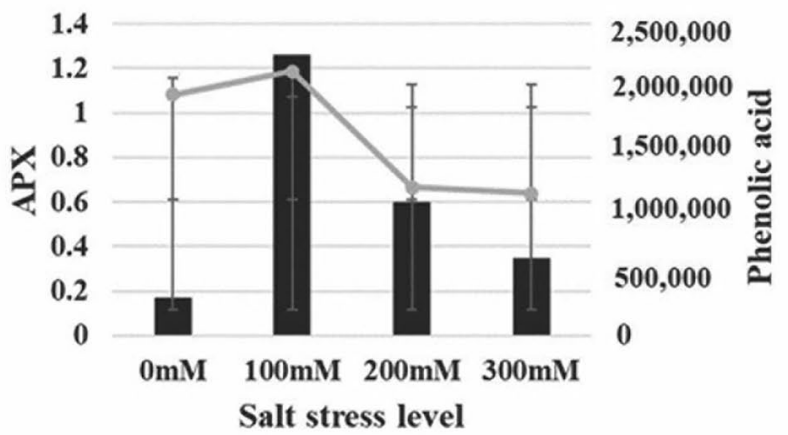

APX $\rightarrow$ Total phenolic acid contents

D

Figure 7. The correlation between antioxidant enzyme activity (superoxide dismutase (SOD, A), peroxidase $(\mathrm{POD}, \mathrm{B})$, catalase (CAT, C), ascorbate peroxidase (APX, D)) and total phenolic acid content under salt stress. 


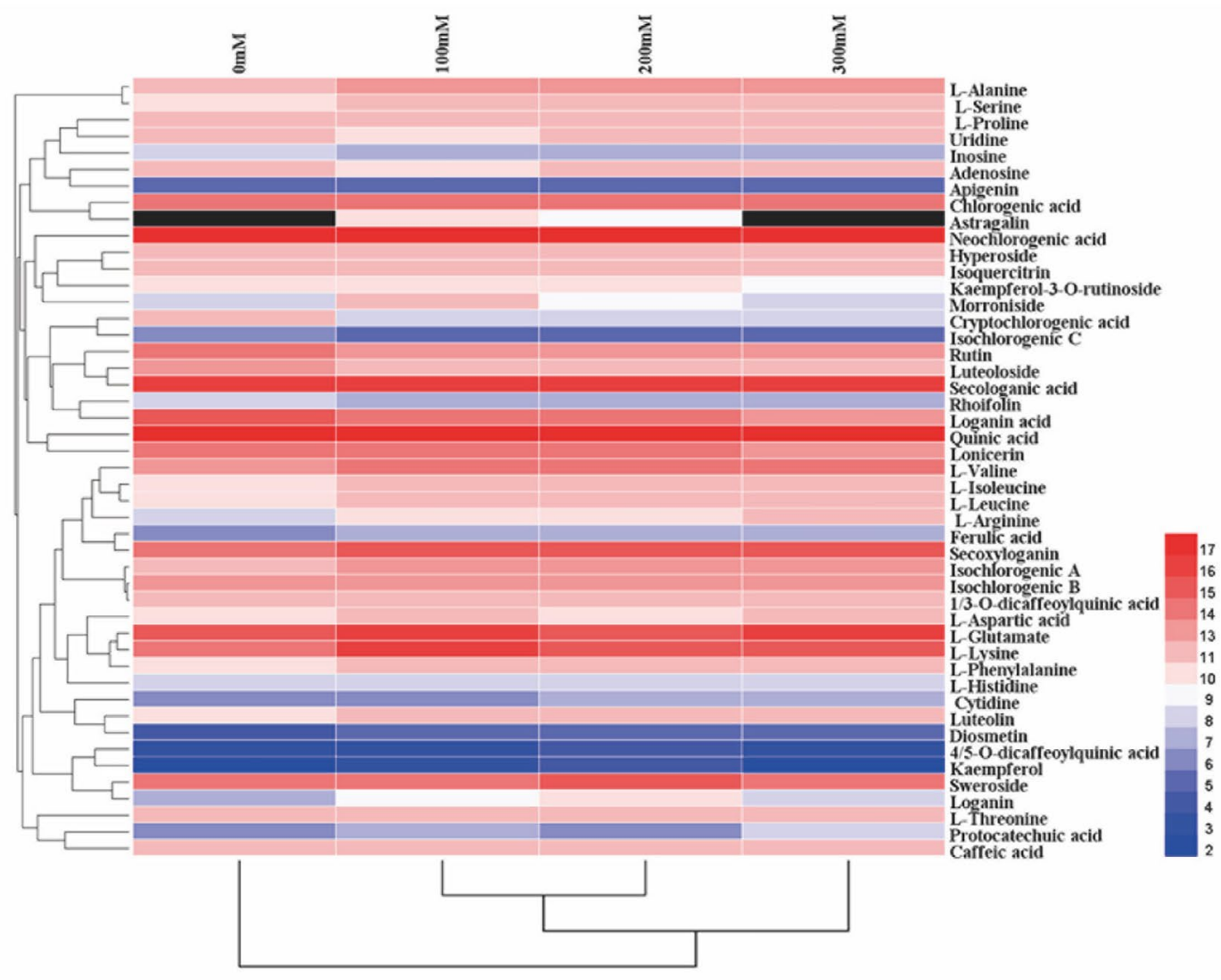

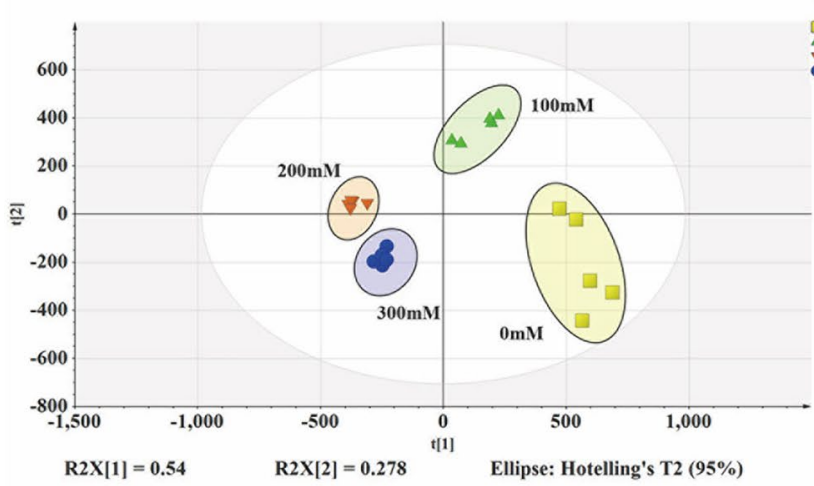

B

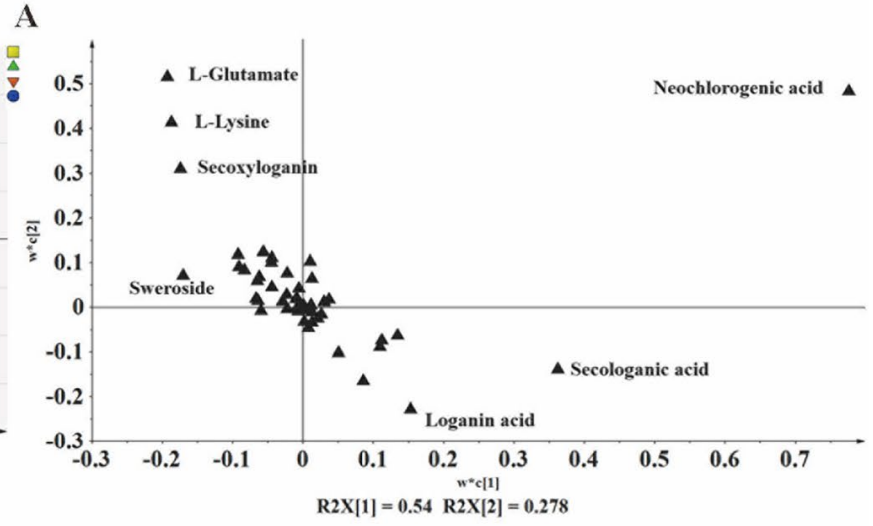

C

Figure 8. Multivariate Statistical Analysis of LJF under different salinity level. hierarchical clustering heat map (A), PLS-DA score plot (B), PLS-DA loading plot (C).

\begin{tabular}{|l|l|l|}
\hline Treatments (mM) & $\boldsymbol{r i}$ & Quality-ranking \\
\hline 0 & 0.52 & 2 \\
\hline 100 & 0.75 & 1 \\
\hline 200 & 0.29 & 3 \\
\hline 300 & 0.25 & 4 \\
\hline
\end{tabular}

Table 3. Quality sequencing of the Lonicerae Japonicae Flos samples affected by $\mathrm{NaCl}$. 
Photosynthesis is a prerequisite for keeping plant normal growth. Therefore, to study the effects of salt stress on photosynthetic parameters is of great significance for improving salt tolerance and the quality of medicinal plants. The strength of photosynthesis can be used as an indicator for judging plant growth and stress resistance $e^{40}$, and the content of Chlorophyll $b$ directly affects the photosynthetic capacity of plants. Here, we find that chlorophyll b concentration peak at $100 \mathrm{mM} \mathrm{NaCl}$. Compared with the control group, the contents of photosynthetic pigments are elevated under low salt stress, but reduced under high salt stress, indicating that low salt stress could boost the photosynthesis of LJF. Conversely, high salt stress inhibits ${ }^{41}$.

It is known that high salt concentration causes osmotic pressure, resulting in an oxidation imbalance in the plant cells; sequentially, causing damage to proteins and cell membrane integrity ${ }^{42}$. In order to mitigate oxidative damage, plants have developed a series of antioxidant responses, including osmotic balance, antioxidant enzymes, and metabolites. The changes in antioxidant enzymes (POD, SOD, APX, and CAT) imply that salt stress stimulates the antioxidant system. The increase of APX activity is accompanied by the increase of SOD, CAT activity, which is referred to as a common regulation for active oxygen scavenging. Also, APX is a key enzyme to protect chloroplasts and other cellular components from $\mathrm{H}_{2} \mathrm{O}_{2}$ and hydroxyl radicals. Our findings revealed that $\mathrm{POD}, \mathrm{SOD}, \mathrm{APX}$, and CAT activity are induced under low salt stress, suggesting that antioxidant enzymes perform a protective effect on preventing adverse reactions. Also, the correlation between phenolic acid contents and antioxidant enzymes under salt stress is consistent with the previous research ${ }^{18}$; our results add further support for this conclusion.

Primary metabolites not only constitute essential nutrients for plant growth, but also protect cellular membranes integrality under salt stress ${ }^{43}$. In this study, the contents of serine, glutamate, and lysine are elevated, which could play a positive role in osmotic adjustments. Parts of nucleosides and their derivatives have significant physiological functions. For instance, inosine is beneficial in the treatment of rheumatic heart disease, acute, and chronic hepatitis. Nucleoside is the main component of nucleic acid. And nucleic acid is the precursor to the synthesis of RNA and DNA. In the study, the contents of nucleoside are relatively lower under salt stress, as salt could cause protein structure changes, increase cytoplasmic RNA enzyme activity, and then lead to a decrease in DNA synthesis ${ }^{44}$. Additionally, Li et al. ${ }^{45}$ discussed the important secondary metabolites and their variation in plants under salt stress in detail, which reveal salt stress improves the accumulation of various secondary metabolites possessing antioxidant activity; such as phenolics and flavonoid metabolites in this study. Phenolic cooperates with the POD to scavenge $\mathrm{H}_{2} \mathrm{O}_{2}$. Flavonoid metabolites clear free radicals with the help of phenolic hydroxyl groups. The phenylpropanoid pathway is the main metabolic pathway for the synthesis of phenolics and flavonoids. Chlorogenic acid and its derivatives are the main phenolic acid constituents and have important quantitative significance both in LJF and other medicinal plants. Previous studies ${ }^{18,46,47}$ have demonstrated that the accumulation and synthesis of chlorogenic acid and luteoloside are directly affected by the variation in hydroxycinnamoyl-Co A quinate hydroxycinamoyl transferase (HQT) and chalcone flavanone isomerase (CHI) activity. Therefore, the correlation between variations of main effective constituents (phenolic acids, flavonoids, and iridoids) contents and the activities of their associated regulatory enzymes under salt stress, which is a promising point and worthy of in-depth study. It is worth mentioning that the content of morroniside increase ninefold under $100 \mathrm{Mm} \mathrm{NaCl}$ treatment and plays a protective role in oxidative stress and myocardial injury. This inspires that even less bioactive constituent content, reprogramming related metabolic pathways through salinity induction also induces the production of these active substances, which provides new clues for improving the quality of medicinal plants. According to the traditional view, the production of secondary metabolites consume a large chunk of energy, which is evident from the plants' limited growth and lipid peroxidation under high salt ${ }^{48}$. Phenolic constituents are regarded as secondary antioxidants and play a vigorous role in detoxifying ROS. In our results, the accumulation of phenolic constituents is induced in low salt stress, while the accumulation is reduced under high salt stress. And Pearson Correlation Coefficient is performed to further verified the correlations. The result show that between phenolic acid contents and SOD, POD activity is significant correlation at $0.01,0.05$ level, respectively. Our findings are in accordance with that the low salinity is beneficial to the accumulation of secondary metabolites and causes little oxidative injury, while high salinity impedes the secondary metabolites production and reduce antioxidative activities in LJF.

Both hierarchical clustering analysis and PLS-DA distinguish LJF samples from different salt stresses, of which compounds marked on the PLS-DA loading plot make it distinguish in different samples. Through GRA analysis, the best quality of LJF is obtained at $100 \mathrm{mM} \mathrm{NaCl}$, followed by 0,200 , and the $300 \mathrm{mM}$. The results illustrate that the quality of LJF treated with $100 \mathrm{mM} \mathrm{NaCl}$ is optimal. The superiority of the control group to other salt stress groups also indicates that excessive salt is not conducive to the quality formation of LJF. Briefly, multivariate statistical analysis provides a basis for the complete differentiation of samples under different salt stresses and LJF quality evaluation.

Generally, salt stress tempestuously affects plant growth, physiological parameter, and metabolic process. However, plants can maintain osmotic balance, avoid oxidative damage, and keep normal growth through a series of adaptive responses. This experiment cultivated LJF under different salt stresses $(0,100,200$, and $300 \mathrm{mM}$ $\mathrm{NaCl}$ ) in the field to investigate the effects on the quality of LJF from the variations of morphology, photosynthesis, osmotic balance, antioxidant activity, bioactive constituents' content. We find that the growth parameters, physiological indicators, and bioactive constituents content get the optimal values at $100 \mathrm{mM} \mathrm{NaCl}$, indicating that salt stress could induce LJF remodeling transcriptional networks and metabolic pathways to regulate its growth and the accumulation of secondary metabolites. This will be verified with the multi-omics approach in the subsequent research. It will deepen acknowledge the mechanism of quality formation in LJF and provide a foundation for cultivation to improve desired characteristics. 


\section{Conclusions}

In the study, a reliable method combining morphology, physiology, and multiple bioactive constituents was proposed to evaluate the quality of LJF under different salt stresses $(0,100,200$, and $300 \mathrm{mM} \mathrm{NaCl})$ based on UFLC-QTRAP-MS/MS and multivariate statistical analysis. The results demonstrated that LJF treated with $100 \mathrm{mM} \mathrm{NaCl}$ had the best quality; the increased accumulation of phenolic acids reduced oxidative damage; and low salt stress $(100 \mathrm{mM})$ promote quality improvement, conversely, high salt $(300 \mathrm{mM})$ inhibited that. Therefore, LJF cultivated in soil with $100 \mathrm{mM} \mathrm{NaCl}$ might be the optimal choice in the long run. Overall, this study sheds light on the effects of different salt stresses on the quality of LJF from the changes in morphology, physiology, and multiple bioactive constituents through field trials. The results might provide an integrated reference for the quality evaluation of other Chinese herbal medicines under salt stress and novel clues for improving the quality of medicinal plants in the pharmaceutical industry.

Received: 28 June 2020; Accepted: 4 February 2021

Published online: 16 February 2021

\section{References}

1. Yang, Y. Q. \& Guo, Y. Elucidating the molecular mechanisms mediating plant salt-stress responses. New Phytol. 217, 523-539 (2018).

2. Dáder, B. et al. Split green fluorescent protein as a tool to study infection with a plant pathogen, Cauliflower mosaic virus. PLoS ONE 14, e0213087 (2019).

3. Nasrollahi, V. N., Mirzaie-asl, A. M., Piri, K., Nazeri, S. \& Mehrabi, R. The effect of drought stress on the expression of key genes involved in the biosynthesis of triterpenoid saponins in liquorice (Glycyrrhiza glabra). Phytochemistry 103, 32-37 (2014).

4. Saito, M. A. et al. Multiple nutrient stresses at intersecting pacifi cocean biomes detected by protein biomarkers. Science $\mathbf{3 4 5}$, 1173-1177 (2014).

5. Spindel, J. E. \& McCouch, S. R. When more is better: how data sharing would accelerate genomic selection of crop plants. New Phytol. 212, 814-826 (2016).

6. Zhang, J. T., Zhang, Y., Du, Y. Y., Chen, S. Y. \& Tang, H. R. Dynamic metabonomic responses of tobacco (Nicotiana tabacum) plants to salt stress. J. Proteome Res. 10, 1904-1914 (2011)

7. Shang, X. F., Hu, P. N. \& Li, M. X. Lonicera japonica Thunb.: thnopharmacology, phytochemistry and pharmacology of an important traditional Chinese medicine. J. Ethnopharmacol. 138, 1-21 (2011).

8. He, L. et al. Transcriptome analysis of buds and leaves using 454 pyrosequencing to discover genes associated with the biosynthesis of active ingredients in Lonicera japonica Thunb. PLoS ONE 8, e62922 (2013).

9. Zhou, Z. et al. Honeysuckle-encoded atypical microRNA2911 directly targets influenza A viruses. Cell Res. 25, 39-49 (2015).

10. Wang, L. N., Jiang, Q., Hu, J. H., Zhang, Y. Q. \& Li, J. Research progress on chemical constituents of Lonicerae japonicae flos. Biomed. Res. Int. https://doi.org/10.1155/2016/8968940 (2016).

11. Slimestad, R., Fossen, T. \& Brede, C. Flavonoids and other phenolics in herbs commonly used in Norwegian commercial kitchens. Food Chem. 309, 125678 (2020).

12. Obied, H. K., Karuso, P., Prenzler, P. D. \& Robards, K. Novel secoiridoids with antioxidant activity from Australian olive mill waste. J. Agric. Food Chem. 55, 2848-2853 (2007).

13. Tian, J., Che, H. L., Ha, D., Wei, Y. P. \& Zheng, S. Y. Characterization and anti-allergic effect of a polysaccharide from the flower buds of Lonicera japonica. Carbohydr. Polym. 90, 1642-1647 (2012).

14. Sun, C. H. et al. Metabolomics study of the protective effects of Lonicera japonica extraction acute liver injury in dimethyl nitrosamine treated rats. J. Pharm. Biomed. Anal. 53, 98-102 (2010).

15. Rawji, K. S. et al. Immunosenescence of microglia and macrophages: impact on the ageing central nervous system. Brain 139, 653-661 (2016).

16. Yang, R. et al. Separation of five iridoid glycosides from Lonicerae Japonicae Flos using high-speed counter-current chromatography and their anti-inflammatory and antibacterial activities. Molecules 24, 197 (2019).

17. Yan, K., Cui, M. X., Zhao, S. J., Chen, X. B. \& Tang, X. L. Salinity stress is beneficial to the accumulation of chlorogenic acids in honeysuckle (Lonicera japonica Thunb.). Front. Plant Sci. 7, 1563 (2016).

18. Yan, K., Zhao, S. J., Bian, L. X. \& Chen, X. B. Saline stress enhanced accumulation of leaf phenolics in honeysuckle (Lonicera japonica Thunb.) without induction of oxidative stress. Plant Physiol. Biochem. 112, 326-334 (2017).

19. Cai, Z. C. et al. Quality evaluation of Lonicerae Japonicae Flos and Lonicerae Flos based on simultaneous determination of multiple bioactive constituents combined with multivariate statistical analysis. Phytochem. Anal. https://doi.org/10.1002/pca.2882 (2019).

20. contribution to the overall antioxidant activity. Seo, O.N. et al. Determination of polyphenol components of Lonicera japonica Thunb. using liquid chromatography-tandem mass spectrometry. Food Chem. 134, 572-577 (2012).

21. Gosa, S. C., Lupo, Y. \& Moshelion, M. Quantitative and comparative analysis of whole-plant performance for functional physiological traits phenotyping: new tools to support pre-breeding and plant stress physiology studies. Plant Sci. 282, 49-59 (2019).

22. Shao, Y. H. et al. Effect of salt treatment on growth, isoenzymes and metabolites of Andrographis paniculata (Burm. F.) Nees. Acta Physiol. Plant. 37, 35 (2015).

23. Yan, K., Wu, C. W., Zhang, L. H. \& Chen, X. B. Contrasting photosynthesis and photoinhibition in tetraploid and its autodiploid honeysuckle (Lonicera japonica Thunb.) under salt stress. Front. Plant Sci. 6, 227 (2015).

24. Lichtenthaler, H. K. \& Wellburn, A. R. Determination of total carotenoids and chlorophylls a and b of leaf in different solvents. Biochem. Soc. Trans. 11, 591-592 (1985).

25. Wang, X. H. \& Huang, J. L. Principles and techniques of plant physiological biochemical experiment 3rd edn. (Higher Education Press, Beijing, 2015).

26. Zeng, J. W. et al. Effects of salt stress on the growth, physiological responses, and glycoside contents of stevia rebaudiana Bertoni. J. Agric. Food Chem. 61, 5720-5726 (2013).

27. Chen, C. H. et al. Variations in physiology and multiple bioactive constituents under salt stress provide insight into the quality evaluation of apocyni veneti folium. Int. J. Mol. Sci. 19, 3042 (2018).

28. Wu, F. B., Zhang, G. P. \& Dominy, P. Four barley genotypes respond differently to cadmium: lipid peroxidation and activities of antioxidant capacity. Environ. Exp. Bot. 50, 67-78 (2003).

29. Cai, Z. C. et al. Comparison of multiple bioactive constituents in the flower and the caulis of Lonicera japonica based on UFLCQTRAP-MS/MS combined with multivariate statistical analysis. Molecules 24, 1936-1951 (2019).

30. Chen, C. H. et al. A strategy for quality evaluation of salt-treated Apocyni Veneti Folium and discovery of efficacy-associated markers by fingerprint-activity relationship modeling. Sci. Rep. https://doi.org/10.1038/s41598-019-52963-3 (2019). 
31. Imada, S., Yamanaka, N. \& Tamai, S. Effects of salinity on the growth, Na partitioning, and Na dynamics of a salt-tolerant tree, Populus alba L. J. Arid Environ. 73, 245-251 (2009).

32. Cheng, S. J., Tang, D. Q., Miller, W. B. \& Shi, Y. M. Evaluation of salinity tolerance in honeysuckle (Lonicera japonica) using growth, ion accumulation, lipid peroxidation, and non-enzymatic and enzymatic antioxidants system criteria. J. Hortic. Sci. Biotechnol. 93, 185-195 (2018).

33. Meloni, D. A., Gulotta, M. R., Martinez, C. A. \& Oliva, M. A. The effects of salt stress on growth, nitrate reduction and proline and glycine betaine accumulation in Prosopis alba. Braz. J. Plant Physiol. 16, 39-46 (2004).

34. Kumar, S., Beena, A. S., Awana, M. \& Singh, A. Physiological, biochemical, epigenetic and molecular analyses of wheat (Triticum aestivum) genotypes with contrasting salt tolerance. Front. Plant Sci. 8, 1151 (2017).

35. Khan, M. A., Ungar, I. A. \& Showalter, A. M. The effect of salinity on the growth, water status, and ion content of a leaf succulent perennial halophyte, Suaeda fruticosa (L.) Forssk. J. Arid Environ. 45, 73-84 (2000).

36. Bavei, V., Shiran, B. \& Arzani, A. Evaluation of salinity tolerance in sorghum (Sorghum bicolor L.) using ion accumulation, proline and peroxidase criteria. J. Plant Growth Regul. 64, 275-285 (2011).

37. Sergio, L. et al. Effect of salt stress on growth parameters, enzymatic antioxidant system, and lipid peroxidation in wild chicory (Cichorium intybus L.). Acta Physiol. Plant. 34, 2349-2358 (2012).

38. Mansour, M. M. F. \& Ali, E. F. Evaluation of proline functions in saline conditions. Phytochemistry 140, 52-68 (2017).

39. Liang, M. H., Liang, Z. C., Chen, H. H. \& Jiang, G. J. The bifunctional identification of both lycopene beta- and epsilon-cyclases from the lutein-rich Dunaliella bardawil. Enzyme Microb. Technol. 131, 109426-109426 (2019).

40. Bendaly, A. et al. Physiological and leaf metabolome changes in the xerophyte species Atriplex halimus induced by salinity. Plant Physiol. Biochem. 103, 208-218 (2016).

41. Munns, R. \& Tester, M. Mechanisms of salinity tolerance. Annu. Rev. Plant Biol. 59, 651-681 (2008).

42. Nabi, R. B. S. et al. Nitric oxide regulates plant responses to drought, salinity, and heavy metal stress. Environ. Exp. Bot. 161, 120-133 (2019).

43. Mishra, A., Patel, M. K. \& Jha, B. Non-targeted metabolomics and scavenging activity of reactive oxygen species reveal the potential of Salicornia brachiata as a functional food. J. Funct. Foods 13, 21-31 (2015).

44. Niu, X., Bressan, R. A., Hasegawa, P. M. \& Pardo, J. M. Ion homeostasis in $\mathrm{NaCl}$ stress environments. Plant Physiol. 109, 735-742 (1995).

45. Li, Y. Q., Kong, D. X., Fu, Y., Sussman, R. M. \& Wu, H. The effect of developmental and environmental factors on secondary metabolites in medicinal plants. Plant J. Physiol. Biochem. 148, 80-89 (2020).

46. Niggeweg, R., Michael, A. J. \& Martin, C. Engineering plants with increased levels of the antioxidant chlorogenic acid. Nat. Biotechnol. 22, 746 (2004).

47. Kong, D. et al. Correlation between the dynamic accumulation of the main effective components and their associated regulatory enzyme activities at different growth stages in Lonicera japonicaThunb. Ind. Crops Prod. 96, 16-22 (2017).

48. Abrol, E., Vyas, D. \& Koul, S. Metabolic shift from secondary metabolite production to induction of anti-oxidative enzymes during $\mathrm{NaCl}$ stress in Swertia chirata Buch.-Ham. Acta Physiol. Plant. 34, 541-546 (2012).

\section{Acknowledgements}

This work was supported by the Priority Academic Program Development of Jiangsu Higher Education Institutions of China (No. ysxk-2014).

\section{Author contributions}

X.L., designed the experiments, helped to write the manuscript and critically revised it. Z.C. C., H.C., R.Y., Jj.C., L.Z., C.W., Jl.C., M.T., Y.M., L.W., conducted the experiments, performed data analysis and wrote the article.

\section{Competing interests}

The authors declare no competing interests.

\section{Additional information}

Supplementary Information The online version contains supplementary material available at https://doi. org/10.1038/s41598-021-83566-6.

Correspondence and requests for materials should be addressed to X.L.

Reprints and permissions information is available at www.nature.com/reprints.

Publisher's note Springer Nature remains neutral with regard to jurisdictional claims in published maps and institutional affiliations.

Open Access This article is licensed under a Creative Commons Attribution 4.0 International License, which permits use, sharing, adaptation, distribution and reproduction in any medium or format, as long as you give appropriate credit to the original author(s) and the source, provide a link to the Creative Commons licence, and indicate if changes were made. The images or other third party material in this article are included in the article's Creative Commons licence, unless indicated otherwise in a credit line to the material. If material is not included in the article's Creative Commons licence and your intended use is not permitted by statutory regulation or exceeds the permitted use, you will need to obtain permission directly from the copyright holder. To view a copy of this licence, visit http://creativecommons.org/licenses/by/4.0/.

(C) The Author(s) 2021 